\title{
Zwitterion-containing polymer additives for fouling resistant ultrafiltration membranes
}

\author{
Papatya Kaner ${ }^{1}$, Emil Rubakh ${ }^{1}$, Do Hyun Kim ${ }^{1}$, Ayse Asatekin ${ }^{1, *}$ \\ ${ }^{1}$ Department of Chemical and Biological Engineering, Tufts University, Medford, MA 02155, \\ USA
}

* Corresponding author. Tel.: +1 617627 4681; Fax: +1 6176273991.

E-mail address: Ayse.Asatekin@tufts.edu (Ayse Asatekin)

(C) 2016. This manuscript version is made available under the Elsevier user license 


\begin{abstract}
Fouling is likely the most important obstacle to the use of membranes in many applications, especially in those that the feed contains high concentrations of organics such as oil and biomacromolecules. Zwitterions, defined as molecules with equal numbers of positively and negatively charged functional groups, show excellent fouling resistance and hydrophilicity. These features can be incorporated into ultrafiltration (UF) membranes during their manufacture by blending a commodity polymer like polyvinylidene fluoride (PVDF) with a copolymer containing zwitterionic groups. This approach can be used directly in existing membrane production systems, with no need for post-processing. Research to date, however, does not provide any guidelines for designing or selecting a zwitterion-containing polymer for this purpose to achieve the best possible performance. In this work, we synthesized copolymers of methyl methacrylate (MMA), whose homopolymer is compatible with PVDF, with two different zwitterionic copolymers, sulfobetaine methacrylate (SBMA) and sulfobetaine-2-vinylpyridine (SB2VP). These copolymers were not previously investigated as surface segregating additives in membrane manufacture. We investigate the impact of different copolymer properties such as zwitterion chemistry, copolymer composition (i.e. zwitterionic/hydrophobic monomer ratio), and blend composition on the performance of membranes manufactured from their blends with PVDF. We report how changing these variables affect the morphology, selectivity, permeance and fouling resistance of membranes, and associate this data with design rules for selecting favorable copolymers. Our study showed that, in contrast to previous literature, increasing the hydrophilic/zwitterionic monomer amount in the additive copolymer does not always result in improved membrane performance. Instead, during membrane formation by non-solvent induced phase separation (NIPS), copolymer additives with high zwitterion content (51-52 wt\%) undergo macrophase separation from PVDF, and the product membrane shows poor performance. On the other hand, with the appropriate copolymers that contain 18-19 wt\% zwitterionic monomer, membranes with significantly higher permeance and remarkable fouling resistance can be attained even with very small amounts of additive copolymer. Zwitterionic additive contents as low as $5 \mathrm{wt} \%$ in PVDF can lead to membranes with doubled water flux (up to $99 \mathrm{~L} / \mathrm{m}^{2}$.h.bar) and complete irreversible fouling resistance against oil suspensions and protein solutions. Only 10 wt $\%$ additive can yield membranes with even higher flux (up to $165 \mathrm{~L} / \mathrm{m}^{2}$.h.bar), and complete resistance to irreversible fouling by an oil suspension in 24-hour dead-end fouling experiments. This degree of fouling resistance have not previously been reported for PVDF-based membranes, to our knowledge, and indicates the promise of this membrane modification approach for a wide range of applications.
\end{abstract}

Keywords: Fouling resistance, ultrafiltration, oil/water separation, PVDF, polymer, zwitterion, water treatment 


\section{Introduction}

Since the early 2000s, potable water shortages have increased worldwide, especially in the developing countries. This challenge has been a major focus for several world bodies, nongovernmental organizations and media reports.[1] Wastewater reclamation and reuse can potentially be a key solution for alleviating water scarcity, particularly in the oil manufacturing regions with dry climate. Many industrial wastewater streams contain oil-in-water suspensions and emulsions. This is an especially important challenge in treating wastewater from oil and gas (produced water), vegetable oil, metal processing, transportation, and petrochemical industries. Ultrafiltration (UF) membranes, whose pore sizes are in the 2-100 nm range, offer remarkable advantages over conventional methods such as hydrocyclones and air flotation in treating oily wastewater: reduced energy use, small footprint and most remarkably, almost complete separation of oil or grease from water.[2] Many past reports have shown the applicability of UF membranes in treating oily wastewater.[3-10]

However, membrane fouling during the UF process in oil/water separation still poses an obstacle to the wider implementation of these systems. Most commercial UF membranes are produced using hydrophobic polymers, highly prone to fouling because of interplay between the membrane surface and foulants. Fouling can lead to $>90 \%$ flux loss in a matter of hours, especially when the feed contains oil or high concentrations of biomolecules such as proteins. It is the most common reason for downtime and membrane replacement.[2, 11, 12] Thus, an urgent need arises for membrane materials and module designs that resist fouling, especially by oily water streams. This led to extensive research on fouling-resistant membranes. Most studied methods of preventing fouling aim to create highly hydrophilic membrane surfaces through surface functionalization, either by post-treatment[13-23] or by surface-segregating additives.[24-32]

Zwitterionic materials are strongly fouling resistant as a result of compactly bound water molecules that are organized as a hydration layer around the zwitterionic head groups.[33] To develop fouling resistant and high flux UF membranes, several groups have incorporated zwitterionic groups on membrane surfaces and shown increased resistance to fouling, specifically by protein solutions. Most of these studies have used surface-initiated polymerization,[13] grafting,[34-39] coating,[19-22] and other post-treatment techniques to modify the surfaces of existing membranes. These methods, however, require additional manufacturing steps that add to the cost of the membrane. Furthermore, the postfunctionalization typically leads to decreased flux as pores are partially filled with the attached functional groups.

In contrast, the application of surface-segregating polymer additives during the manufacture of membranes by non-solvent induced phase inversion (NIPS) allows improved fouling resistance without additional processing steps. During precipitation in water, the amphiphilic copolymer segregates to the polymer-water interface, such as the membrane top surface and pore walls, to minimize the surface energy. This affords these surfaces hydrophilicity and fouling resistance, even within internal pores not accessed by most grafting and coating methods.[24-31] Thus, amphiphilic polymer additives can provide excellent resistance to organic fouling, improved wettability, and significantly higher permeance if the system is designed well.[24-27, 40, 41]

A handful of studies have utilized this approach using a zwitterionic copolymer blended with the 
base polymer of choice.[42-51] First examples of these studies have focused on blends of polyacrylonitrile (PAN) with PAN-based random copolymers featuring sulfobetaine methacrylate (SBMA), [42, 43] sulfobetaine methacrylamide (SBMAm), [44] or phosphorylcholine[45] moieties. A few studies using polyvinylidene fluoride (PVDF), a more commonly used membrane material due to its chemical resistance and mechanical properties, have recently been undertaken.[46, 49-52] One study prepared the graft copolymer PVDF-gSBMA using ATRP and blended it with PVDF to prepare membranes by NIPS. The copolymer composition was not quantified, and while flux and fouling resistance improved with increasing copolymer content, they were relatively minor.[46] Two studies prepared the random copolymer PMMA-r-SBMAm and prepared hollow fiber membranes using thermally induced phase separation (TIPS). The resultant membranes showed no change in flux or pore size, and no measurable improvement in fouling resistance in filtration tests, though some reduction in protein adsorption was observed in static fouling tests.[49, 50] Another prepared random copolymers of SBMAm with a partially fluorinated methacrylate monomer, and prepared membranes from its blends with PVDF. Some compositions showed good fouling resistance. While a hypothesis on higher performance at intermediate hydrophobic/zwitterionic monomer ratios was presented, it was not substantiated with any data.[52] The final study addressed challenges in identifying a common solvent for PVDF and a zwitterionic copolymer by introducing an ionic liquid as a co-solvent, yet did not perform any fouling resistance studies.[51] None of these studies have led to membranes with good fouling resistance, or aimed to find structure-property relationships that enable targeted design and development of zwitterionic copolymers and membrane manufacture methods using zwitterionic copolymers. In addition, most studies have focused on protein fouling resistance only,[42-44, 46-50, 53] leaving out the significant issue of oil fouling during oil/water separation. To the best of our knowledge, there has been only one study that shows the antifouling capability of surface segregating zwitterionic additives during the separation of oil/water emulsion, only using one-hour filtration tests.[52] To understand the exact mechanism of fouling resistance and surface-segregation of zwitterionic polymer additives, systematic studies that screen long-term fouling runs and link these results to fundamental polymer science are needed.

In this work, we aim to better understand how chemical compositions of zwitterionic copolymer/PVDF blends affect the performance of membranes prepared from them. Research to date does not provide any guidelines for designing or selecting a zwitterion-containing polymer to be used as a membrane additive to achieve the best possible performance. Thus, we investigate the impact of different copolymer properties such as zwitterion chemistry, copolymer composition (i.e. zwitterionic/hydrophobic monomer ratio), and blend composition on resulting membranes features, and thus membrane performance and fouling resistance.

For this purpose, we synthesized several random/statistical copolymers of zwitterionic and hydrophobic monomers varying these parameters, blended them with the base PVDF at different ratios, and analyzed the morphology, permeance, selectivity and fouling resistance of manufactured membranes. We chose to use the random/statistical copolymer architecture, where the hydrophobic and zwitterionic groups are scattered essentially randomly along the same polymeric backbone, due to its easy, reliable and scalable synthesis. As the hydrophobic component of these copolymers, we selected poly(methyl methacrylate) (PMMA) due to its excellent compatibility with PVDF. [54, 55] We chose two sulfobetaine-type zwitterionic monomers that are zwitterionic over the complete $\mathrm{pH}$ range:[56] sulfobetaine methacrylate 
(SBMA) and sulfobetaine-2-vinyl-pyridine (SB2VP). Both of these copolymers were used as membrane formation additives for the first time in this study, to our knowledge. SBMA is a commercially available zwitterionic monomer that has been extensively used in past studies, mostly as a component of random copolymers.[42, 57] It is a good initial material to start with, but is susceptible to acid- or base-catalyzed hydrolysis and oxidation due to the ester group linking the zwitterion to the polymerizable group.[58] This means that in membrane applications, its usefulness may be limited to mild $\mathrm{pH}$ levels. To circumvent these issues, we explored an additional zwitterionic monomer, SB2VP that has not, to our knowledge, been used in the membrane field to date. We expect SB2VP to be much better adapted to handle harsh cleaning conditions due to no hydrolysable groups between the vinyl and sulfobetaine groups, along with the presence of an aromatic ring that will provide further oxidation resistance.[59]

UF membranes were prepared from blends of PVDF and the synthesized zwitterionic copolymers by NIPS. The morphology of all membranes were determined using Scanning Electron Microscopy (SEM). Dead end filtration tests were used to characterize the permeance and protein rejection of each membrane as well as their resistance to fouling by a protein solution and a model oil-in-water emulsion. Attenuated Total Reflection - Fourier Transform Infrared Spectroscopy (ATR-FTIR) and thermal analysis methods were used to evaluate the crystallization behavior and macrophase separation tendency of the copolymer/PVDF blends. Our analyses showed that increasing the hydrophilic/zwitterionic monomer content in the additive copolymer does not always lead to improved membrane performance. Macrophase separation from PVDF during NIPS prevents the formation of robust membranes at high zwitterion content, whether in the copolymer or in the overall blend. On the other hand, with the right approach, blend membranes showing remarkably high permeance and fouling resistance to both oil and protein can be attained with zwitterionic additive quantities as small as 5 wt $\%$ in PVDF.

\section{Experimental}

\subsection{Materials}

Sulfobetaine methacrylate (SBMA), methyl methacrylate (MMA), 2-vinylpyridine, 1,3propanesultone, azobisisobutyronitrile (AIBN), monomethyl ether of hydroquinone (MEHQ), bovine serum albumin (BSA, $66.5 \mathrm{kDa}$ ), phosphate buffered saline (PBS) and sodium hydroxide $(\mathrm{NaOH})$ were purchased from Sigma Aldrich (St. Louis, MO). Poly(vinylidene fluoride) (PVDF, average $\mathrm{M}_{\mathrm{w}} \sim 180,000$ by GPC, average $\mathrm{M}_{\mathrm{n}} \sim 71,000$ beads or pellets) was also obtained from Sigma Aldrich (St. Louis, MO), and used as base polymer in forming the blend membranes. Basic activated alumina, dimethyl sulfoxide (DMSO), toluene, ethanol (EtOH), hexane, trifluoroethanol (TFE), and methanol (MeOH) were all acquired from VWR (West Chester, PA). Deuterated dimethyl sulfoxide $\left(\mathrm{DMSO}-\mathrm{d}_{6}\right)$ was purchased from Cambridge Isotope Laboratory (Tewksbury, MA). DC193 surfactant was purchased from Dow Chemicals (Providence, RI). All chemicals and solvents were reagent grade and used as received, except MMA, which was passed through a basic activated alumina column to remove any inhibitor. PV200 ultrafiltration membranes obtained from Nanostone Inc. (Oceanside, CA) were used as control in short term fouling resistance tests. 


\subsection{Synthesis of zwitterionic amphiphilic copolymers}

\subsubsection{Synthesis of PMMA-r-SBMA copolymers}

Random/statistical copolymers of MMA and zwitterionic SBMA monomers were synthesized by free radical polymerization (FRP), following a similar procedure from our past study.[53] In each synthesis, total monomer mass in the starting mixture was $30 \mathrm{~g}$. Methyl methacrylate (MMA) was dissolved in DMSO to make a $25 \mathrm{wt} \%$ solution at room temperature, and SBMA was dissolved in DMSO to make a $5 \mathrm{wt} \%$ solution at $60{ }^{\circ} \mathrm{C}$ then brought back to room temperature. These solvated monomers were mixed at the desired feeding ratio in a $500 \mathrm{ml}$ round bottom flask and $0.03 \mathrm{~g}$ azobisisobutyronitrile (AIBN) initiator was added to the monomer mix. After ensuring that the starting materials were fully dissolved, the reaction mixture was purged with nitrogen for at least $30 \mathrm{~min}$. Then, the reaction mixture was stirred at $320 \mathrm{rpm}$ for 20 hours at $70{ }^{\circ} \mathrm{C}$. To stop the reaction at the end of 20 hours, the contents were exposed to air and $1.5 \mathrm{~g}$ inhibitor MEHQ was also added. Then, the reaction mixture was precipitated into a 1:1 mixture of hexane and ethanol, followed by three methanol washes for removing any residual monomers. The white solid polymer obtained was dried for two days under the fume hood and two more days in vacuum oven at $50{ }^{\circ} \mathrm{C}$. Chemical characterization was conducted by ${ }^{1} \mathrm{H}-\mathrm{NMR}$ using

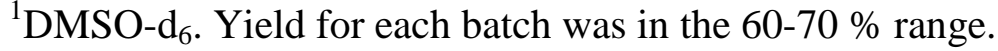

\subsubsection{Synthesis of PMMA-r-SB2VP copolymers}

PMMA-r-SB2VP was synthesized following a similar procedure to that described above. The zwitterionic monomer SB2VP was synthesized following previously reported procedures.[60] In each synthesis, total monomer mass in the starting mixture was $30 \mathrm{~g}$. MMA was dissolved in trifluoroethanol (TFE) to make a $20 \mathrm{wt} \%$ solution at room temperature, and SB2VP was separately dissolved in TFE to make an $8 \mathrm{wt} \%$ solution at room temperature also. The monomer solutions were mixed at the desired feeding ratio in a $250 \mathrm{ml}$ round bottom flask and $0.03 \mathrm{~g}$ AIBN initiator was added to the monomer mix. After ensuring that the starting materials were fully dissolved, the reaction mixture was purged with nitrogen for at least $30 \mathrm{~min}$. The reaction mixture was then stirred at $320 \mathrm{rpm}$ for 48 hours at $60{ }^{\circ} \mathrm{C}$. To stop the reaction at the end of 48 hours, the contents were exposed to air and $1.5 \mathrm{~g}$ inhibitor MEHQ was added. Then, the reaction mixture was precipitated into a 1:1 mixture of hexane and ethanol, followed by three methanol washes for removing any residual monomers. The pinkish solid polymer obtained was dried two days under the fume hood and two more days in vacuum oven at $50{ }^{\circ} \mathrm{C}$. Chemical characterization was conducted by ${ }^{1} \mathrm{H}-\mathrm{NMR}$ using DMSO- $\mathrm{d}_{6}$. Yield for each batch was in the 60$70 \%$ range.

\subsection{Molecular weight (Mw) characterization}

The molecular weight of the copolymers was estimated by dynamic light scattering (DLS) (Malvern Zetasizer Nano) measurements. The light source of the instrument was a $35 \mathrm{~mW}$ red diode laser with a nominal wavelength of $633 \mathrm{~nm}$. All the measurements were conducted using 1 $\mathrm{mg} / \mathrm{ml}$ copolymer solutions in dimethyl sulfoxide (DMSO) at a scattering angle of $90^{\circ}$ and at temperature $25{ }^{\circ} \mathrm{C}$. The copolymer solutions were filtered with a $0.2 \mu \mathrm{m}$ filter to eliminate dust prior to light scattering experiments. For each copolymer ratio, three measurements were performed following a stabilization period of two minutes. The effective hydrodynamic radii values were used in determining the relative molecular weights based on polyacrylonitrile (PAN) 
standards in dimethyl formamide (DMF) by employing the Mark-Houwink equation. The MarkHouwink parameters used for PAN in DMF at $25^{\circ} \mathrm{C}$ were $\mathrm{K}=2.43 \times 10^{-2}$ and $\mathrm{a}=0.75$.[61]

\subsection{Preparation of blend membranes with zwitterionic additives}

UF membranes were cast from blends of PVDF (obtained from Sigma Aldrich Inc.) and the synthesized zwitterionic PMMA-r-SBMA or PMMA-r-SB2VP copolymers by non-solvent induced phase separation (NIPS). Dimethyl sulfoxide (DMSO) was used as the solvent medium because it could successfully dissolve both the PVDF base and zwitterionic additives. To prepare the membrane casting solutions, the zwitterionic additive was allowed to dissolve completely in DMSO at approximately $70{ }^{\circ} \mathrm{C}$ first. Once dissolved, PVDF was added into the copolymer solution and stirred overnight at $70{ }^{\circ} \mathrm{C}$. Zwitterionic copolymer:PVDF ratios were fixed at 5:95, 10:90, and 15:85 by mass, totaling a $3 \mathrm{~g}$ total polymer in $17 \mathrm{~g}$ DMSO solvent. The casting solutions were degassed in a vacuum oven set at $50{ }^{\circ} \mathrm{C}$ for at least 24 hours. The blend membranes were formed by casting a film of the mixed polymer solution onto a glass plate (McMaster-Carr) using an adjustable doctor blade (Gardco) set to a 150 micrometer gate size, followed by immersion into a DI water bath at room temperature for 20 minutes to precipitate out the polymer blend. After this period, the membranes were moved to a fresh DI water bath mixed with bisulfite preservative and stored at least overnight before use. As a control, additivefree PVDF membrane was manufactured by dissolving $3 \mathrm{~g}$ PVDF in $17 \mathrm{~g}$ DMSO and following the NIPS procedure explained above.

\subsection{Membrane morphology}

Membrane morphology was characterized by the examination of freeze-fractured cross-sections of the membranes using a scanning electron microscope (SEM, Phenom G2 Pure Tabletop SEM). Cross-sections of the membranes were attained by first dipping the membrane in liquid nitrogen, and then breaking it using a clean razor blade. All samples were sputter-coated with gold-palladium alloy prior to imaging. All SEM images were acquired at magnification 2000x.

\subsection{Surface hydrophilicity}

Contact angle (CA) measurements were performed using the captive air bubble method to follow the changes in membrane surface hydrophilicity with use of different zwitterionic additives. The membranes, which were all flat sheets, were mounted on a glass slide, and they were immersed in DI water upside down. For the captive air bubble method, a $2-\mu \mathrm{L}$ air bubble was dispensed from the tip of a U-shaped needle and placed on the surface of the water-immersed membrane. A Ramé-Hart contact angle instrument (Ramé-Hart Instrument Co.) equipped with a horizontal microscope and camera connected to a video screen was used for the measurements. For each data point reported, a minimum of five measurements was recorded using different sections of the membrane.

\subsection{Membrane permeability and protein rejection}

All filtration experiments were conducted with an Amicon 8010 stirred, dead-end filtration cell (Millipore) with a cell volume of $10 \mathrm{~mL}$ and an effective filtration area of $4.1 \mathrm{~cm}^{2}$, connected to a 3.5-L dispensing vessel. In water permeability tests, the membrane was first allowed to stabilize by filtering deionized (DI) water at least overnight under 10 psi (0.07 MPa) pressure. Data shown in the filtration plots was collected after the stabilization period. The cell was stirred 
at $500 \mathrm{rpm}$ using a stir plate, and $10 \mathrm{psi}(0.07 \mathrm{MPa})$ pressure was applied during filtration. The permeate weight collected every 30 seconds was automatically recorded using a Scout Pro SP401 balance connected to TWedge 2.4 software (TEC-IT, Austria). Permeances of the membranes were obtained by normalizing the flux by the filtration pressure.

For characterizing protein rejection and quantifying fouling resistance, a model foulant solution comprising $1 \mathrm{~g} / \mathrm{L}$ bovine serum albumin (BSA, $66.5 \mathrm{kDa}$ ) in phosphate buffer saline (PBS, $\mathrm{pH}$ 7.4) was filtered for two hours. The filtrate was used to calculate rejection, expressed as

$$
\mathrm{R}=\frac{100\left(\mathrm{C}_{\mathrm{f}}-\mathrm{C}_{\mathrm{p}}\right)}{\mathrm{C}_{\mathrm{f}}}
$$

Where $\mathrm{R}$ is the protein rejection $(\%), \mathrm{C}_{\mathrm{f}}$ is the feed concentration $(\mathrm{mg} / \mathrm{L})$, and $\mathrm{C}_{\mathrm{p}}$ is the permeate concentration $(\mathrm{mg} / \mathrm{L})$. Protein concentration in the feed and filtrate was quantified by measuring the UV absorbance at $280 \mathrm{~nm}$ utilizing a Thermo Scientific Genesys 10S UV-Vis spectrophotometer equipped with a high-intensity xenon lamp and dual-beam optical geometry.

\subsection{Fouling resistance}

Prior to all fouling tests, the membrane was stabilized by filtering deionized (DI) water at least overnight under $10 \mathrm{psi}(0.07 \mathrm{MPa})$ pressure. Data shown in the filtration plots was collected after the stabilization period. All fouling tests were performed using the same set up described above for permeability measurements. For testing fouling resistance against oil, a $1500 \mathrm{mg} / \mathrm{L}$ oil-inwater emulsion (9:1 ratio of soybean oil:DC193 surfactant) was prepared.[62] Short-term resistance tests against oil fouling involved the following 2-hour steps: (1) Filter DI water to determine the initial flux, (2) filter the prepared oil-in-water emulsion, and (3) after rinsing the cell and the membrane several times with DI water, filter DI water again to compare fluxes before and after oil-in-water emulsion filtration. For testing long-term fouling resistance against oil, the oil-in-water emulsion filtration in second step was conducted for 24 hours while all the other steps were kept the same.

In fouling resistance tests against proteins, model foulant solution comprised $1 \mathrm{~g} / \mathrm{L}$ bovine serum albumin (BSA, $66.5 \mathrm{kDa}$ ) in phosphate buffer saline (PBS, pH 7.4). Short-term resistance tests against protein fouling involved the 2-hour steps: (1) Filter DI water to determine the initial flux, (2) filter phosphate buffer saline (PBS) solution, (3) filter bovine serum albumin (BSA, 66.5 $\mathrm{kDa}$ ) foulant solution to simulate protein fouling, (4) after rinsing the membrane and cell several times with PBS solution, filterPBS, and (5) filter DI water again to compare fluxes before and after fouling. For testing long-term fouling resistance against proteins, the BSA solution filtration in third step was conducted for 24 hours while all the other steps were kept the same.

\subsection{Chemical characterization of the top surface of blend membranes}

The chemistry of the top $\sim 1 \mu \mathrm{m}$ section of blend membranes was analyzed using Attenuated total reflection Fourier transform infrared (ATR-FTIR) spectroscopy. All membranes were dried in air before analysis. The ATR-FTIR spectra were acquired using a Jasco FTIR-6200 Spectrometer (Jasco Instruments, Tokyo, Japan), equipped with a deuterated triglycine sulfate detector and a multiple-reflection, horizontal MIRacle ATR accessory. The spectra were analyzed using the instrument's SpectraManager software in absorption mode at $4 \mathrm{~cm}^{-1}$ resolution with 256 scans 
between 2000-600 $\mathrm{cm}^{-1}$. Background absorption was subtracted from the sample spectra to set the baseline.

\subsection{Thermal analysis of the blend membranes}

Differential Scanning Calorimetry (DSC) was employed to conduct thermal analysis of the blend membranes. Samples with mass of about $10 \mathrm{mg}$ were cut from each membrane and encapsulated in aluminum pans. The crystallization, melting and glass transition temperatures of the polymers were characterized using a TA Instruments Q100 DSC, which was purged with dry nitrogen gas at a flow rate of $50 \mathrm{~mL} / \mathrm{min}$. All measurements were conducted in standard DSC mode using the following program: (1) Decrease the temperature down to $-80{ }^{\circ} \mathrm{C}$, (2) keep the sample at $-80{ }^{\circ} \mathrm{C}$ for $5 \mathrm{~min}$, (3) heat the sample from $-80{ }^{\circ} \mathrm{C}$ to $240{ }^{\circ} \mathrm{C}$ at $10{ }^{\circ} \mathrm{C} / \mathrm{min}$, (4) keep the sample at $240{ }^{\circ} \mathrm{C}$ for $5 \mathrm{~min}$, (5) cool the sample from $240{ }^{\circ} \mathrm{C}$ to $-80{ }^{\circ} \mathrm{C}$ at $10{ }^{\circ} \mathrm{C} / \mathrm{min}$, (6) keep the sample at $-80{ }^{\circ} \mathrm{C}$ for $5 \mathrm{~min}$, and (7) heat the sample again from $-80{ }^{\circ} \mathrm{C}$ to $240{ }^{\circ} \mathrm{C}$ at $10{ }^{\circ} \mathrm{C} / \mathrm{min}$. The melting endotherms acquired in seventh step of the thermal protocol were analyzed to obtain the glass transition temperature $\left(\mathrm{T}_{\mathrm{g}}\right)$, melting temperature $\left(\mathrm{T}_{\mathrm{m}}\right)$, and latent heat of fusion $\left(\Delta \mathrm{H}_{\mathrm{m}}\right)$ of the blends. The peaks of the cooling exotherms acquired in fifth step were also analyzed to obtain the crystallization temperature $\left(\mathrm{T}_{\mathrm{c}}\right)$, and heat of crystallization $\left(\Delta \mathrm{H}_{\mathrm{c}}\right)$.

\subsection{Chemical and mechanical stability of the membranes}

To test the chemical stability of the membranes, water permeance and chemical composition by ATR-FTIR were analyzed before and after storing the membranes in $0.1 \mathrm{M} \mathrm{NaOH}$ solution for 14 days.

The mechanical stability of membranes was characterized using burst pressure measurements. Membrane permeance was recorded at pressures increased by $10 \mathrm{psi}(0.07 \mathrm{MPa})$ increments, from $10 \mathrm{psi}(0.07 \mathrm{MPa})$ to $50 \mathrm{psi}(0.35 \mathrm{MPa})$. The pressure that the membrane showed an abrupt increase in permeance was determined as the burst pressure.

\section{Results and Discussion}

\subsection{Synthesis and characterization of copolymers}

The random/statistical zwitterionic copolymers PMMA-r-SBMA and PMMA-r-SB2VP were synthesized using free radical copolymerization following a single-step reaction scheme (Fig. 1). This synthesis scheme is robust and easily scalable, allowing for lower technical barriers to large-scale synthesis of these copolymers for commercialization. 


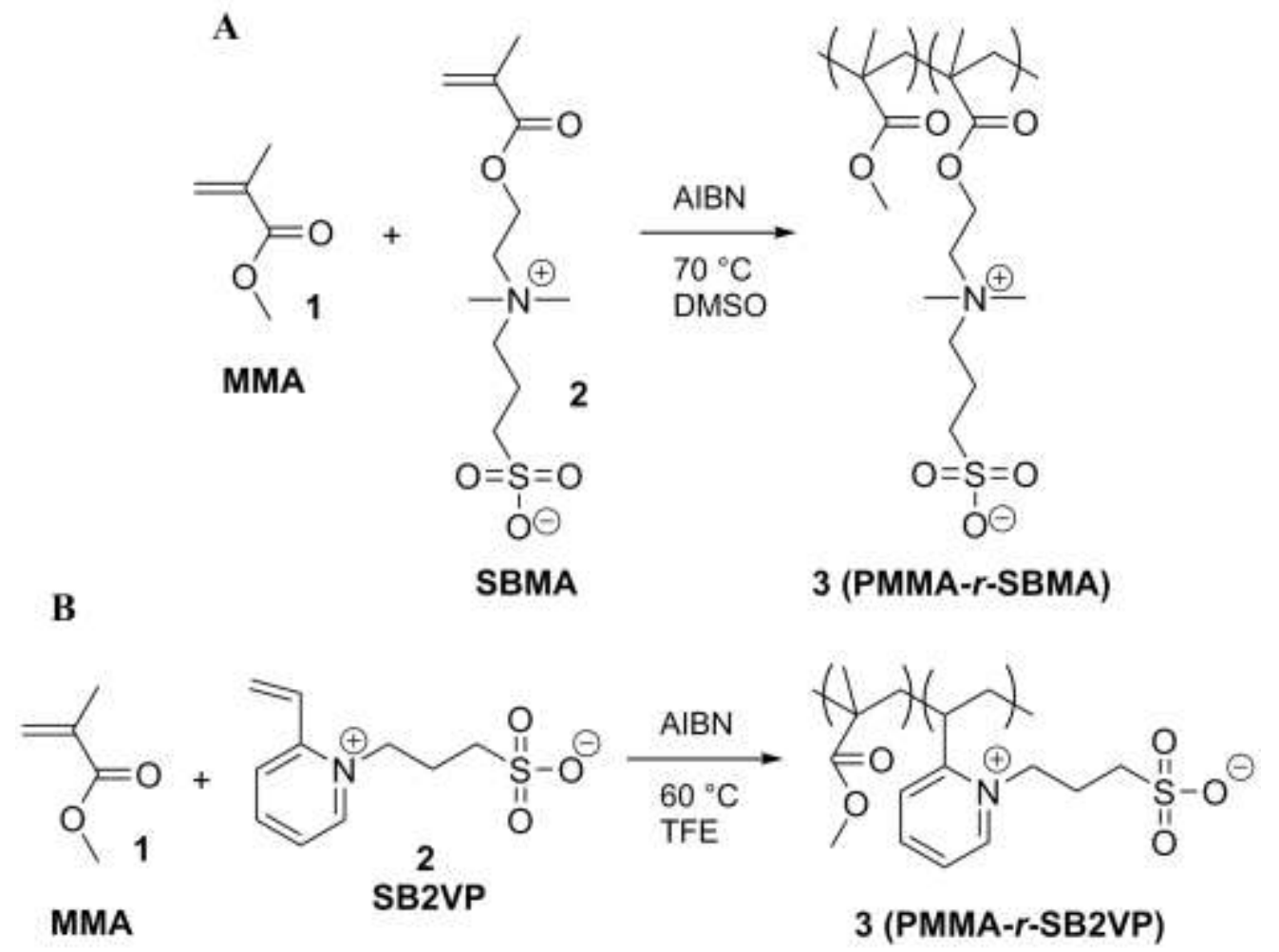

Fig. 1. Synthesis scheme for the random zwitterionic copolymers (a) PMMA-r-SBMA, and (b) PMMA-r-SB2VP

Two batches of each of the PMMA- $r$-SBMA and PMMA- $r$-SB2VP copolymers were prepared at different compositions. The PMMA-r-SBMA copolymer had 19 or $52 \mathrm{wt} \%$ SBMA in the final product, and these synthesized copolymers are named as SBMA19 and SBMA52 (Table 1). The PMMA-r-SB2VP copolymer had 18 or $51 \mathrm{wt} \%$ SB2VP in the final product, and these copolymers are named as SB2VP18 and SB2VP51 (Table 1). Sample 1H-NMR spectra, used for characterizing the chemical composition of the resultant copolymers, are shown in Fig. 2 for the SBMA19 and SB2VP18 copolymers with all peak assignments marked. NMR spectra of the SBMA52 and SB2VP51 copolymers are given in Appendix A, Fig. A.1. All copolymers were white and glassy, soluble in DMSO, and insoluble in DI water. The copolymers SBMA52 and SB2VP51 were found to be partially soluble in PBS solution, whereas copolymers SBMA19 and SB2VP18 were not. This is driven by the fact that zwitterion-containing polymers are known to be ionic strength responsive, with their hydrophilicity and solubility increasing in the presence of small salt ions.[33] Higher zwitterion contents emphasize this effect, leading to increased solubility in the high salinity PBS.

In free radical copolymerization, the final composition of the copolymer and the sequence of repeat units along the backbone are determined by the reactivity ratios of the monomer pair. While the exact reactivity ratios were not determined for this study, the general correlation between reaction mixture composition and final copolymer composition can give significant indications to this, especially because the copolymers were isolated at 60-70\% conversion, before all monomer is incorporated into the copolymer. PMMA-r-SBMA copolymer contents were obtained to be within $\sim 5 \%$ of monomer composition in the reaction mixture (Table 1 ). 
While the reactivity ratios can be further characterized, these results imply that the copolymerization is essentially random.[63] For the PMMA-r-SB2VP copolymers, our initial screening showed that the copolymer gets slightly enriched in SB2VP in comparison with the reaction mixture used. Thus, we started with reaction mixtures containing $15 \mathrm{wt} \%$ and $40 \mathrm{wt} \%$ SB2VP monomer, respectively, to attain copolymers with $\sim 20 \mathrm{wt} \%$ and $\sim 50 \mathrm{wt} \%$ SB2VP. This likely indicates the resultant statistical copolymers may contain short blocks of SB2VP, at a ratio higher than expected for a truly random copolymer. It should be noted that while these copolymers are truly statistical copolymers with the given caveats, we use the term "random copolymer" throughout this document for the sake of simplicity and to use consistent terminology with past publications in the field, where this effect was not considered.

Table 1 Compositions of the reaction mixture and properties of the synthesized zwitterionic copolymers

\begin{tabular}{|c|c|c|c|c|c|c|c|c|}
\hline \multirow[b]{2}{*}{$\begin{array}{l}\text { Polymer } \\
\text { name }\end{array}$} & \multicolumn{4}{|c|}{ Reaction mixture composition } & \multirow[b]{2}{*}{$\begin{array}{l}\text { Reac. } \\
\text { temp. }\end{array}$} & \multirow[b]{2}{*}{$\begin{array}{l}\text { Reac. } \\
\text { time }\end{array}$} & \multicolumn{2}{|c|}{ Copolymer properties } \\
\hline & MMA & $\begin{array}{l}\text { SBMA/ } \\
\text { SB2VP }\end{array}$ & AIBN & $\begin{array}{l}\text { DMSO } \\
\text { or TFE }\end{array}$ & & & $\begin{array}{l}\text { MMA:zwitterionic } \\
\text { monomer mass } \\
\text { ratio }\end{array}$ & $\begin{array}{c}\mathrm{Mw} \\
(\mathrm{g} / \mathrm{mol})\end{array}$ \\
\hline SBMA19 & $24 \mathrm{~g}$ & $6 \mathrm{~g}$ & $0.03 \mathrm{~g}$ & $170 \mathrm{~mL}$ & $70^{\circ} \mathrm{C}$ & $20 \mathrm{~h}$ & $81: 19$ & $3.0 \times 10^{5}$ \\
\hline SBMA52 & $15 \mathrm{~g}$ & $15 \mathrm{~g}$ & $0.03 \mathrm{~g}$ & $300 \mathrm{~mL}$ & $70{ }^{\circ} \mathrm{C}$ & $20 \mathrm{~h}$ & $48: 52$ & $1.6 \times 10^{6}$ \\
\hline SB2VP18 & $25.5 \mathrm{~g}$ & $4.5 \mathrm{~g}$ & $0.03 \mathrm{~g}$ & $110 \mathrm{~mL}$ & $60^{\circ} \mathrm{C}$ & $48 \mathrm{~h}$ & $82: 18$ & $3.1 \times 10^{5}$ \\
\hline SB2VP51 & $18 \mathrm{~g}$ & $12 \mathrm{~g}$ & $0.03 \mathrm{~g}$ & $150 \mathrm{~mL}$ & $60{ }^{\circ} \mathrm{C}$ & $48 \mathrm{~h}$ & $49: 51$ & $2.5 \times 10^{5}$ \\
\hline
\end{tabular}
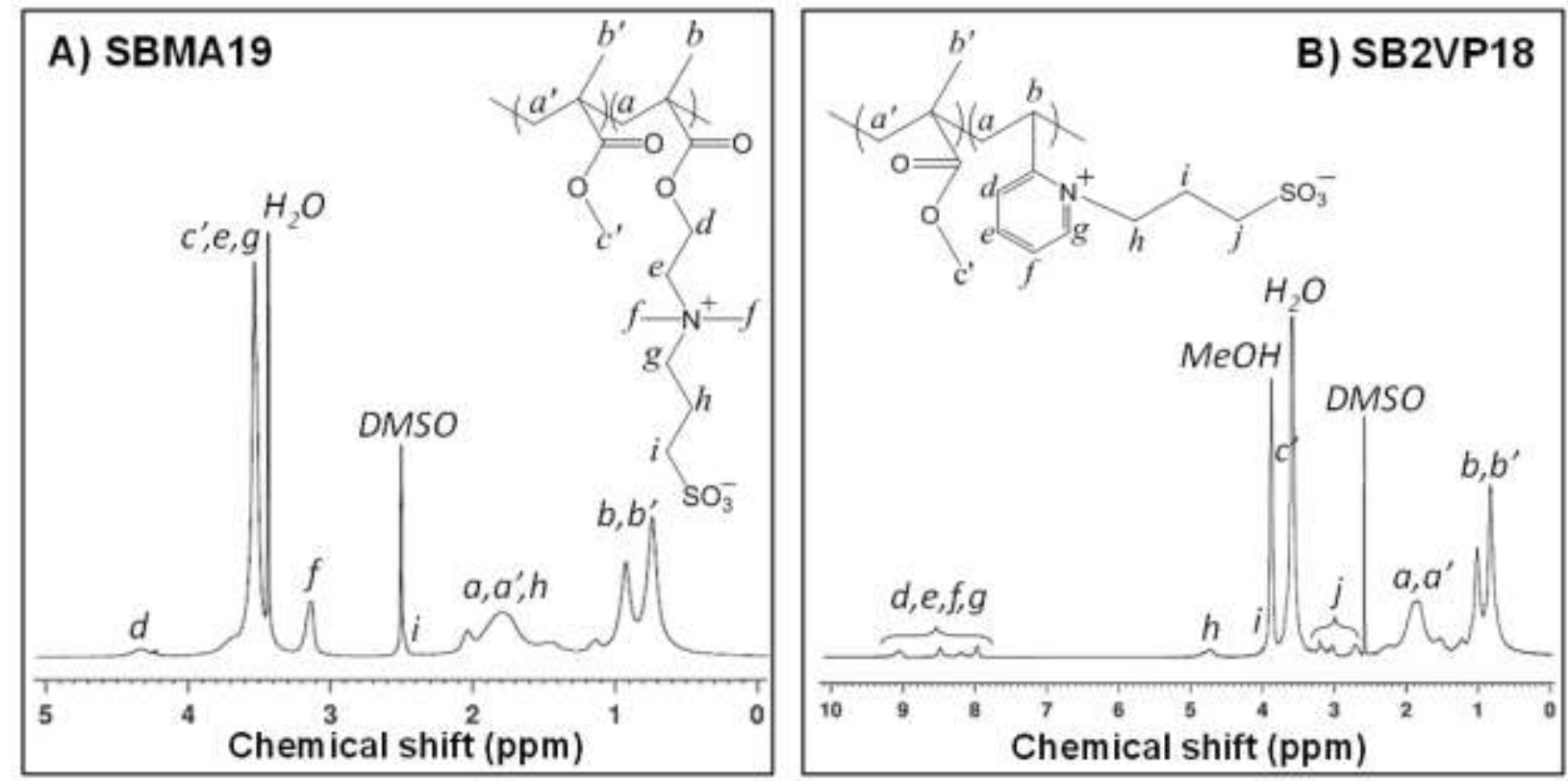

Fig. 2. ${ }^{1} \mathrm{H}-\mathrm{NMR}$ spectrum of the random zwitterionic copolymers (a) SBMA19, and (b) SB2VP18

The molecular weight of the copolymers was estimated by conducting dynamic light scattering (DLS) measurements on $1 \mathrm{mg} / \mathrm{ml}$ solutions of the copolymers in dimethyl sulfoxide. The 
effective hydrodynamic radii of SBMA19, SBMA52, SB2VP18 and SB2VP51 copolymers were $48.9 \pm 7 \mathrm{~nm}, 131.3 \pm 5 \mathrm{~nm}, 49.5 \pm 3 \mathrm{~nm}$ and $44.4 \pm 2 \mathrm{~nm}$, respectively. The Mark-Houwink equation was employed to convert these to the relative molecular weights based on polyacrylonitrile standards in dimethyl formamide at $25{ }^{\circ} \mathrm{C}\left(\mathrm{K}=2.43 \times 10^{-2}\right.$ and $\left.\mathrm{a}=0.75\right)$.[61] The calculated molecular weights are $3.0 \times 10^{5} \mathrm{~g} / \mathrm{mol}, 1.6 \times 10^{6} \mathrm{~g} / \mathrm{mol}, 3.1 \times 10^{5} \mathrm{~g} / \mathrm{mol}$ and $2.5 \times 10^{5} \mathrm{~g} / \mathrm{mol}$ for SBMA19, SBMA52, SB2VP18 and SB2VP51 copolymers (Table 1), respectively. Although these molecular weights are not absolute values due to the solvent-dependent polymeric chain conformations, they serve as reliable order-of-magnitude estimates.

\subsection{Preparation and morphology of blend membranes with zwitterionic additives}

Polyvinylidene fluoride (PVDF) is one of the most widely used membrane materials in UF systems due to its excellent chemical and oxidation resistance and thermal stability, in addition to its strong mechanical integrity. However, its hydrophobic nature, which allows for deposition of foulants on the membrane surface and permeability loss, obstructs the broader use and commercialization of PVDF membranes.[64] This substantially increases the energy need per volume of filtrate, raising energy costs. PVDF membranes that are fouling-resistant, therefore, are one of the key solutions that could lead to sustainable UF membrane processes and costeffective wastewater reclamation.

In this study, we aimed to cast UF membranes from blends of PVDF and zwitterionic copolymers by NIPS. To form a robust blend membrane comprising a zwitterionic copolymer additive and PVDF base, the hydrophobic part of the additive copolymer needs to be at least partially miscible with the PVDF base. PMMA is known to show excellent compatibility with PVDF[54, 55] due to dipole-dipole and hydrogen bonding interactions between the carbonyl groups of PMMA and the $\mathrm{CF}_{2}$ and $\mathrm{CH}_{2}$ groups of PVDF. This decreases the risk of polymerpolymer macrophase separation during the membrane precipitation process, where the domain size for two incompatible polymers can be as large as some tens of $\mu \mathrm{m}$.[65] PMMA itself or PMMA-based random, block and comb-shaped copolymers have been employed as additives to enhance the fouling resistance of PVDF membranes.[24, 26, 49-51, 65-70] Zwitterion-containing copolymers of PMMA have been used for this objective in a handful of studies, with mixed results.[49-51] Here, we cast UF membranes from blends of PVDF and the synthesized random PMMA- $r$-SBMA and PMMA- $r$-SB2VP copolymers by NIPS. All blend membranes manufactured, together with the control PVDF membranes (M-PVDF and PV200), are reported in Table 2. 
Table 2 Blend and control PVDF membranes used in this study

\begin{tabular}{|c|c|c|c|}
\hline Membrane series & Membrane code & Additive & Additive:PVDF ratio \\
\hline \multirow{3}{*}{ M-SBMA19 } & $\mathrm{M}_{5: 95-\mathrm{SBMA19}}$ & \multirow{3}{*}{ SBMA19 } & $5: 95$ \\
\hline & M $_{10: 90-S B M A 19}$ & & $10: 90$ \\
\hline & $\mathrm{M}_{15: 85}$-SBMA19 & & $15: 85$ \\
\hline \multirow{3}{*}{ M-SBMA52 } & $\mathrm{M}_{5: 95-\mathrm{SBMA52}}$ & \multirow{3}{*}{ SBMA52 } & $5: 95$ \\
\hline & $\mathrm{M}_{10: 90-\mathrm{SBMA52}}$ & & $10: 90$ \\
\hline & $\mathrm{M}_{15: 85-\mathrm{SBMA52}}$ & & $15: 85$ \\
\hline \multirow{3}{*}{ M-SB2VP18 } & $\mathrm{M}_{5: 95-\mathrm{SB} 2 \mathrm{VP} 18}$ & \multirow{3}{*}{ SB2VP18 } & $5: 95$ \\
\hline & $\mathrm{M}_{10: 90^{-}} \mathrm{SB} 2 \mathrm{VP} 18$ & & $10: 90$ \\
\hline & $\mathrm{M}_{15: 85-\mathrm{SB} 2 \mathrm{VP} 18}$ & & $15: 85$ \\
\hline \multirow{3}{*}{ M-SB2VP51 } & $\mathrm{M}_{5: 95-\mathrm{SB} 2 \mathrm{VP} 51}$ & \multirow{3}{*}{ SB2VP51 } & $5: 95$ \\
\hline & $\mathrm{M}_{10: 90-\mathrm{SB} 2 \mathrm{VP} 51}$ & & $10: 90$ \\
\hline & $\mathrm{M}_{15: 85}$-SB2VP51 & & $15: 85$ \\
\hline Home-made PVDF & M-PVDF & None & $0: 100$ \\
\hline Commercial PVDF & PV200 & - & - \\
\hline
\end{tabular}

Overall membrane thicknesses are reported in Appendix A, Table A.1, and were between 65-100 $\mu \mathrm{m}$. Fig. 3 shows cross-sectional SEM images of blend membranes, and the control M-PVDF membrane. Cross-sectional morphologies typical of asymmetric UF membranes are obtained in all cases. All membranes exhibit a thin layer of dense, small voids, supported by a $\sim 60-90 \mu \mathrm{m}$ thick layer comprising larger tubular macrovoids. Some of the membrane samples, especially the membranes prepared without any zwitterionic copolymer additives, show a second, denser porous sublayer beneath the macrovoids. This layer, which may lead to lower permeance, disappears upon addition of the SBMA19 or SB2VP18 additives as macrovoids span the entire membrane thickness. Interestingly, this denser sublayer persists for the additives with high zwitterion content. Thus, membranes prepared with the copolymer additives containing 20wt $\%$ zwitterionic monomer exhibit more favorable membrane morphology, at least for the casting conditions used in this study.

The SEM cross-sections of the membranes $\mathrm{M}_{10: 90}$-SBMA52 and $\mathrm{M}_{15: 85}$-SBMA52 showed spherical enclosures of polymer below the membrane surface. This may suggest potential separation of the zwitterionic additive from the PVDF host during precipitation in NIPS process, creating macrophase separated domains within the porous polymer matrix. The presence of these heterogeneous regions may lead to significant decline in membrane performance. 

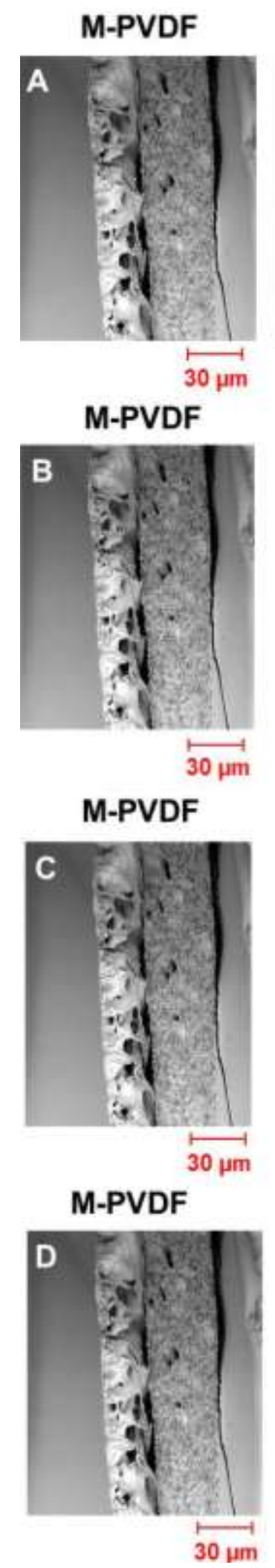
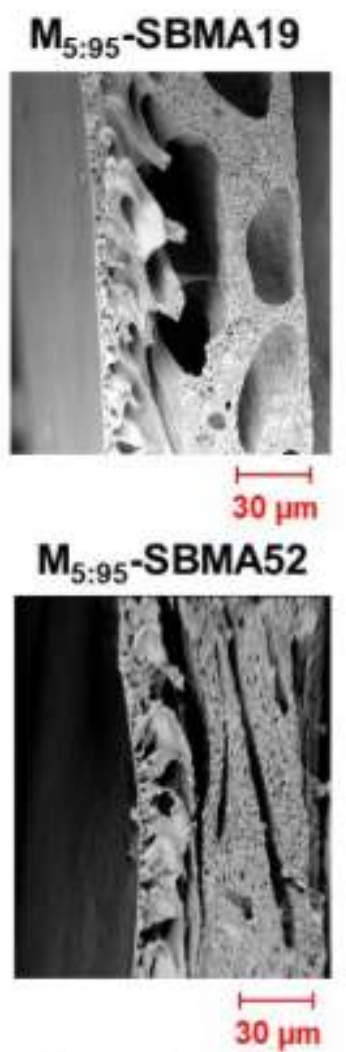

$\mathrm{M}_{5: 95}$-SB2VP18
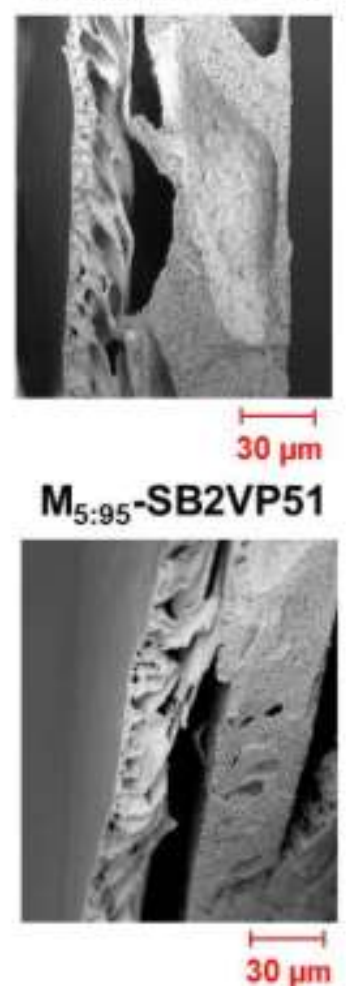
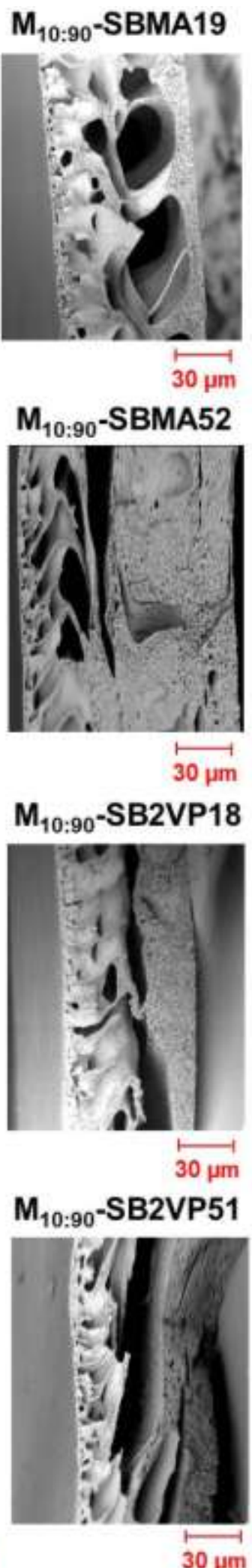

$M_{15: 85}$-SBMA19

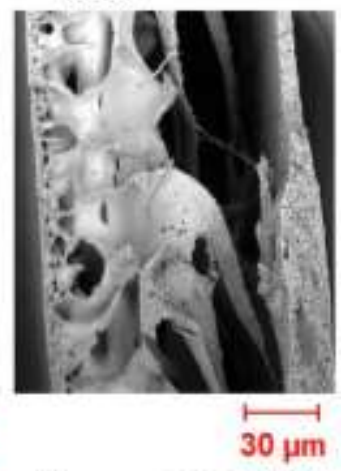

$M_{15: 85}$-SBMA52

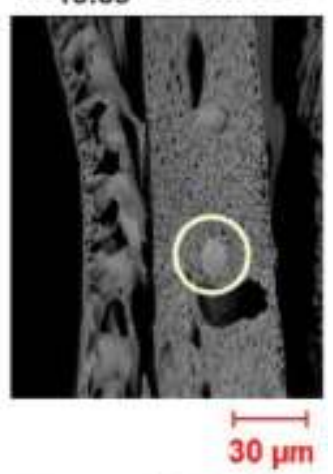

$M_{15: 85}-S B 2 V P 18$
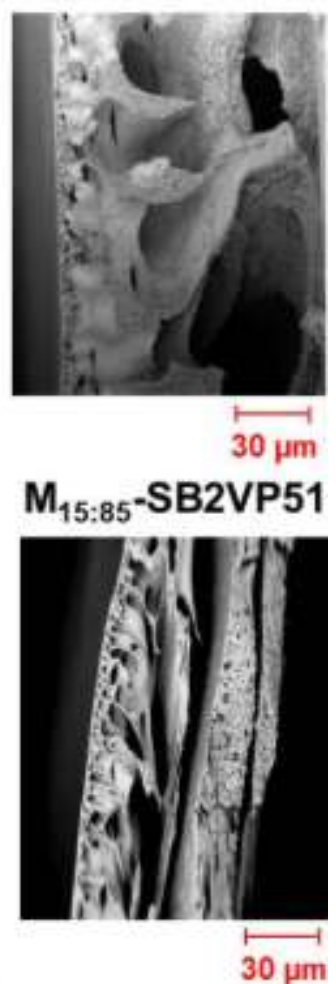

Fig. 3. Cross-sectional SEM images of membranes with varying amounts of zwitterionic copolymer additives. From left to right (a) M-PVDF, M-SBMA19 series, (b) M-PVDF, M-SBMA52 series, (c) MPVDF, M-SB2VP18 series, and (d) M-PVDF, M-SB2VP51 series. 


\subsection{Surface hydrophilicity of the blend membranes}

The surface hydrophilicity of the blend membranes was affected by the addition of zwitterionic copolymers to PVDF, as expected. Fig. 4 shows the contact angle measurements, performed using the captive air bubble method, of M-SBMA19 and M-SB2VP18 series prepared using 5:95 and 10:90 additive:PVDF ratio along with the home-made control M-PVDF. M-PVDF had the highest contact angle $\left(93^{\circ} \pm 4^{\circ}\right)$, confirming the hydrophobic nature of its surface. The captive air bubble contact angle in both series decreased significantly with the addition of just 5 wt $\%$ zwitterionic copolymer (5:95 additive:PVDF ratio). This confirms that the blend membrane surfaces are more hydrophilic due to the segregation of zwitterionic groups onto the membrane surface. On the other hand, increasing the zwitterionic additive amount to $10 \mathrm{wt} \%$ (10:90 additive:PVDF ratio) led to only a slight further enhancement of surface hydrophilicity. The use of $15 \mathrm{wt} \%$ zwitterionic copolymer (15:85 additive:PVDF ratio) in M-SBMA19 and M-SB2VP18 series lead to a decline in surface hydrophilicity (Appendix A, Table A.2) with a high standard deviation in contact angles. At this high concentration, the zwitterionic copolymer is likely poorly dispersed in PVDF, forming macrophase separated domains and thus localized zwitterionic regions on the membrane surface. Contact angle measurements of all membranes in M-SBMA52 and M-SB2VP51 series also showed results in this vein (Appendix A, Table A.2). In both of these series, no significant change in contact angle was observed with increasing additive content along with large standard deviations. This is again potentially due to the macrophase separation of the copolymer additive, in agreement with other data described in this manuscript.

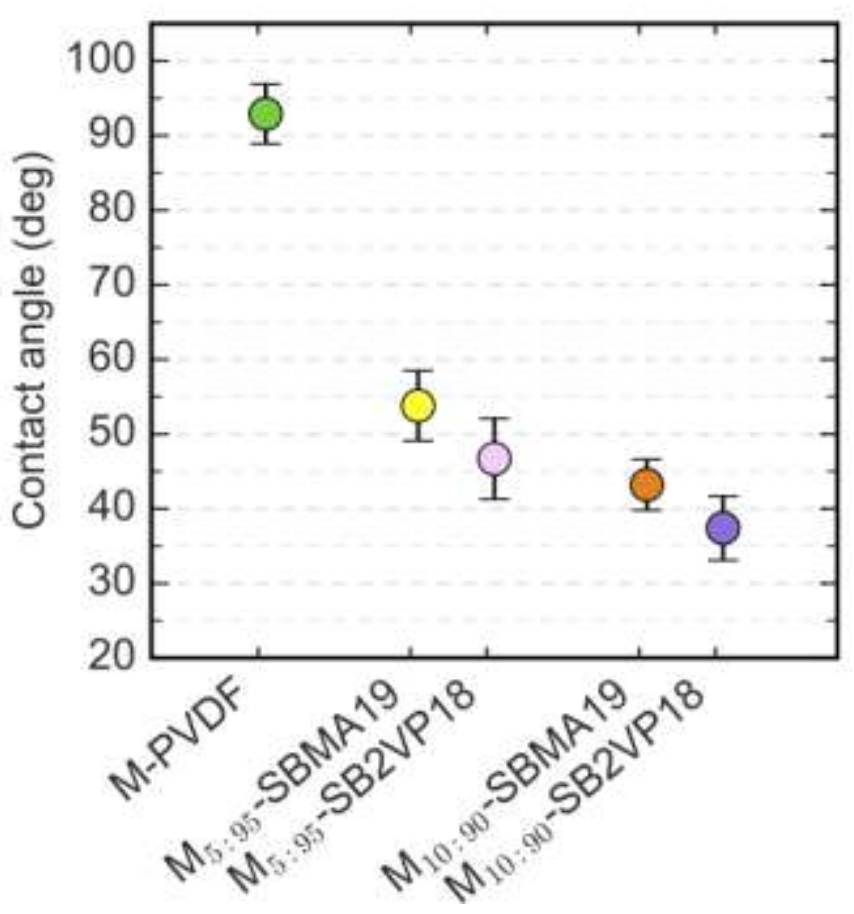

Fig. 4. Contact angle of membrane series M-SBMA19 and M-SBMA18, prepared with lowzwitterion-content copolymer additives, along with the control M-PVDF 


\subsection{Water permeance and protein rejection of the blend membranes}

The selectivity and pure water flux of prepared membranes are expected to be affected by the changes in membrane morphology and chemistry upon the addition of zwitterionic random copolymers to PVDF. Pure water permeance and percentage BSA rejection of all blend membranes are reported in Table 3 along with the control PVDF membranes (M-PVDF and PV200).

Table 3 Pure water permeance and BSA rejection of blend and control PVDF membranes

\begin{tabular}{|c|c|c|c|}
\hline Membrane series & Membrane code & $\begin{array}{l}\text { Pure water } \\
\text { permeability } \\
\left(\mathrm{L} / \mathrm{m}^{2} \text {.h.bar }\right)\end{array}$ & $\begin{array}{l}\text { BSA rejection } \\
\text { after } 2 \mathrm{~h}(\%)\end{array}$ \\
\hline \multirow{2}{*}{ M-SBMA19 } & $\mathrm{M}_{5: 95-\mathrm{SBMA19}}$ & $99 \pm 5$ & $99 \pm 3$ \\
\hline & $\mathrm{M}_{10: 90}$-SBMA19 & $165 \pm 10$ & $99 \pm 1$ \\
\hline \multirow{2}{*}{ M-SBMA52 } & $\mathrm{M}_{5: 95-\mathrm{SBMA52}}$ & $114 \pm 10$ & - \\
\hline & $\mathrm{M}_{10: 90-\mathrm{SBMA52}}$ & $144 \pm 14$ & - \\
\hline \multirow{2}{*}{ M-SB2VP18 } & $\mathrm{M}_{5: 95-\mathrm{SB} 2 \mathrm{VP} 18}$ & $86 \pm 8$ & $93 \pm 1$ \\
\hline & $\mathrm{M}_{10: 90-\mathrm{SB} 2 \mathrm{VP} 18}$ & $148 \pm 8$ & $86 \pm 6$ \\
\hline \multirow{2}{*}{ M-SB2VP51 } & $\mathrm{M}_{5: 95-\mathrm{SB} 2 \mathrm{VP} 51}$ & $275 \pm 29$ & - \\
\hline & $\mathrm{M}_{10: 90-\mathrm{SB} 2 \mathrm{VP} 51}$ & $564 \pm 42$ & - \\
\hline Additive-free PVDF & M-PVDF & $48 \pm 3$ & $92 \pm 4$ \\
\hline Commercial PVDF & PV200 & $153 \pm 9$ & $98 \pm 2$ \\
\hline
\end{tabular}

The water permeance of the additive-free PVDF membrane prepared following the same procedure as that for the blend membranes, M-PVDF, was much lower than those of the membranes prepared with copolymer additives. Its BSA rejection differed significantly from some blend membranes also (Table 3). Fouling is strongly dependent on membrane flux and the rejection of the foulant. Higher permeances tend to lead to more fouling, especially in dead-end experiments. Low foulant rejection can lead to internal pore fouling. Thus, we chose to include an additional control membrane in our study. A commercial PVDF UF membrane whose permeance and BSA rejection was comparable with membrane series prepared with 10:90 copolymer:PVDF ratio was also selected as a control (PV200, Table 2 and Table 3).

In the case of M-SBMA19 and M-SB2VP18 series prepared with low-zwitterion-content copolymer additives, water permeability increased with zwitterionic additive content up to and additive:PVDF ratio of 10:90 (Fig. 5). Addition of only 5 wt\% SBMA19 or SB2VP18 with respect to PVDF (5:95 additive:PVDF ratio) to the casting solution led the permeability to rise to approximately twice its initial value (Fig. 5). For both $\mathrm{M}_{10: 90}$-SBMA19 and $\mathrm{M}_{10: 90}$-SB2VP18 membranes, the permeability was found to increase to over three times that of the M-PVDF membrane. This increase is likely associated with the changes in membrane morphology (Fig. 3) and improved hydrophilicity (Fig. 4). Despite the higher water permeances observed and larger macrovoids in the support layer, the membranes with SBMA19 and SB2VP18 additives showed similar BSA rejections ranging between $86 \%$ and $99 \%$, suitable for UF applications and similar to that of the commercial UF membrane PV200. The increased water flux is a remarkable benefit of these membranes for commercialization purposes. Widely used methods of surface 
modification using zwitterionic groups such as grafting[13, 14, 34, 35, 39, 71, 72] or coating[1921] often lead to a decline in membrane permeability as pores are blocked by the added brush or coating. They also involve post-processing, which would add to the manufacturing costs.
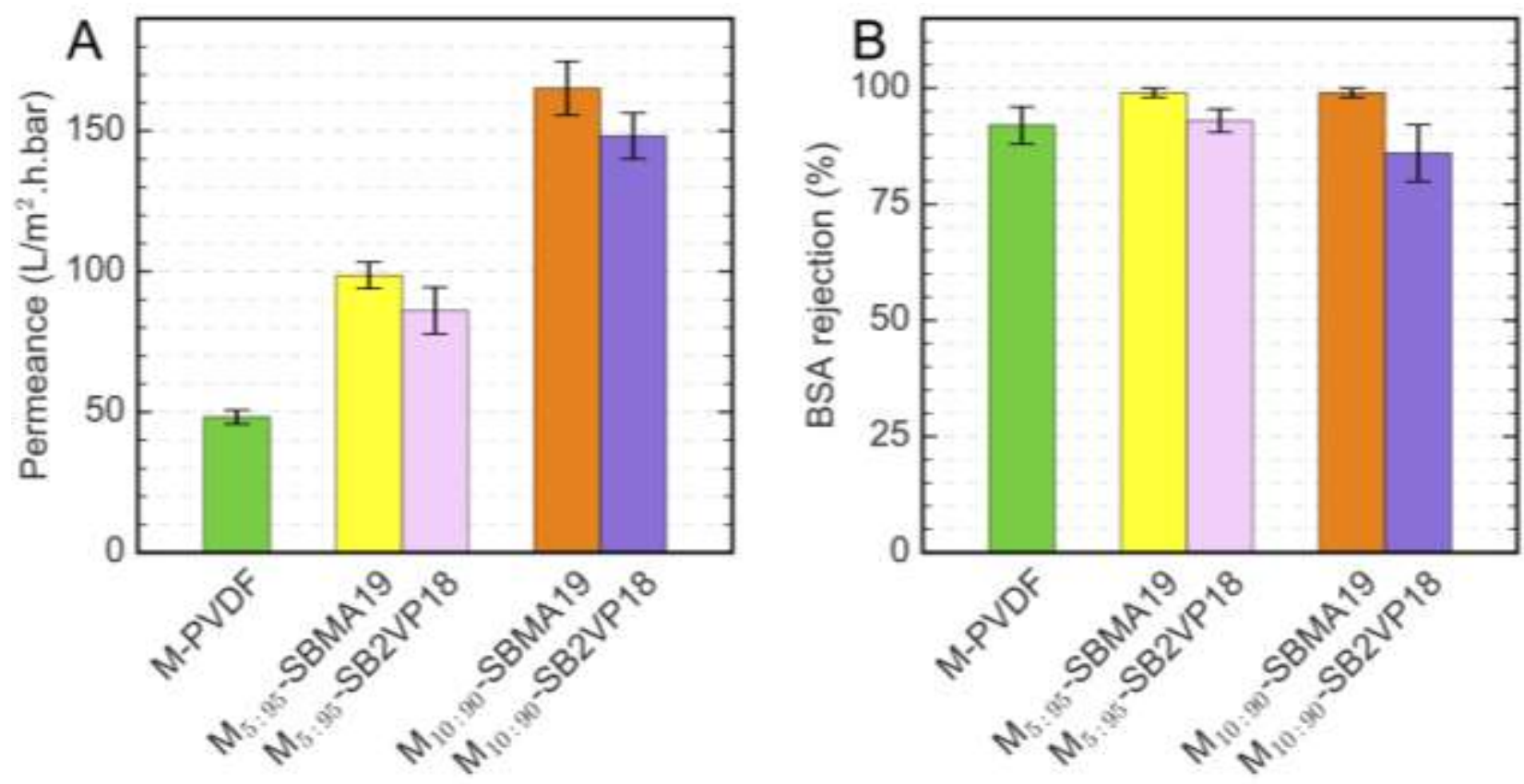

Fig. 5. (a) Pure water permeance, and (b) BSA rejection of membrane series M-SBMA19 and MSBMA18, prepared with low-zwitterion-content copolymer additives, along with control M-PVDF

The addition of either copolymer at 15:85 additive:PVDF ratio resulted in flimsy, mechanically weak membranes with poor filtration performance. These samples were not further characterized in terms of performance.

Interestingly, increasing zwitterion content in the PMMA-r-SBMA additive did not lead to any further improvement in the pure water permeability of the blend membranes, indicated by the similarity between the results obtained from the M-SBMA52 and M-SBMA19 series. Increasing zwitterion content in the PMMA-r-SB2VP additive seemingly led to a significant increase in permeability, but these results were deemed not reliable due to poor membrane stability observed in this membrane series M-SB2VP51. In testing BSA rejection, filtration experiments have to be conducted with BSA dissolved in PBS solution to prevent protein aggregation. The BSA rejection could not be measured in high zwitterion membrane series, M-SBMA52 and MSB2VP51, because the additive copolymers, SBMA52 and SB2VP51, were found to dissolve in PBS.

\subsection{Short-term fouling resistance with oil emulsions}

Fouling is an important bottleneck in broader application of UF membranes for oily water treatment.[73] Thus, we aimed to identify membrane formulations that resisted fouling by oily water streams. For an initial screening, $2 \mathrm{~h}$ dead-end fouling tests were carried out using oil-inwater emulsions as the feed. Fig. 6 shows the change in normalized flux with time for a $2 \mathrm{~h}$ deadend filtration of all blend membranes along with the commercial PVDF control membrane PV200. Here, normalized flux is represented as the ratio of the instant flux to the pure water flux 
at the end of the compaction period (Table 3). This parameter was selected to better visualize changes in flux during fouling, and flux recovery upon rinsing with water. Table A.3 in Appendix A reports the initial water permeance, final oil emulsion permeance, water permeance after DI water rinse, total oil emulsion filtered through the membrane and turbidity removal.

Changes in flux during the filtration of the foulant solution can arise from multiple causes including concentration polarization, the formation of a cake layer or a thin film of oil above the membrane, and membrane fouling due to the adsorption of oil and/or surfactant molecules. The first two of these parameters are dominated by hydrodynamics in the membrane module and can be tackled by optimizing operating conditions and careful module design. Flux recovery upon a water rinse, chosen to simulate a physical cleaning process, allows us to identify the contribution of adsorptive, irreversible membrane fouling, which is mainly controlled by membrane surface chemistry.

During the filtration of the oil-in-water emulsion, the normalized flux of the M-SBMA19 and MSB2VP membranes remained similar to that of the commercial PV200 membrane. Upon rinsing the membrane and cell and switching to a water feed, M-SBMA19 and M-SB2VP18 membranes recovered their initial fluxes, indicating that irreversible fouling could be fully prevented, despite the observed loss of flux during operation. All observed fouling could be reversed, within error margin, with a simple water rinse, with no need for chemical cleaning methods. This also implies that adsorptive fouling was negligible for these membranes. In comparison, the control membrane PV200 lost $20 \%$ of its initial flux irreversibly. To recover its initial performance, this commercial PVDF UF membrane would require chemical cleaning. It should be noted that while normalized fluxes during operation were similar in this dead-end experiment. In a well-designed module that limits concentration polarization and cake fouling, a higher flux may potentially be maintained for these membranes due to lack of adsorptive fouling.

In the case of M-SBMA52 and M-SB2VP51 membranes, the normalized flux was found to fall significantly below that of the PV200 membrane during oil-in-water emulsion filtration. Upon switching to a water feed, it was observed that $\mathrm{M}_{5: 95}$-SBMA52 and $\mathrm{M}_{10: 90}$-SBMA52 membranes lost $25 \%$ and $30 \%$ of their initial flux, respectively. $\mathrm{M}_{5: 95}-\mathrm{SB} 2 \mathrm{VP5} 1$ and $\mathrm{M}_{10: 90-\mathrm{SB} 2 \mathrm{VP} 51}$ membranes lost $44 \%$ and $56 \%$ of their initial flux, respectively. These results are indicative of adsorptive fouling at least comparable with the commercial PV200 membrane. This suggests that increasing zwitterionic content in the additive copolymer above $\sim 20 \%$ does not necessarily lead to an improvement in the membrane performance, and may even cause a performance drop. 

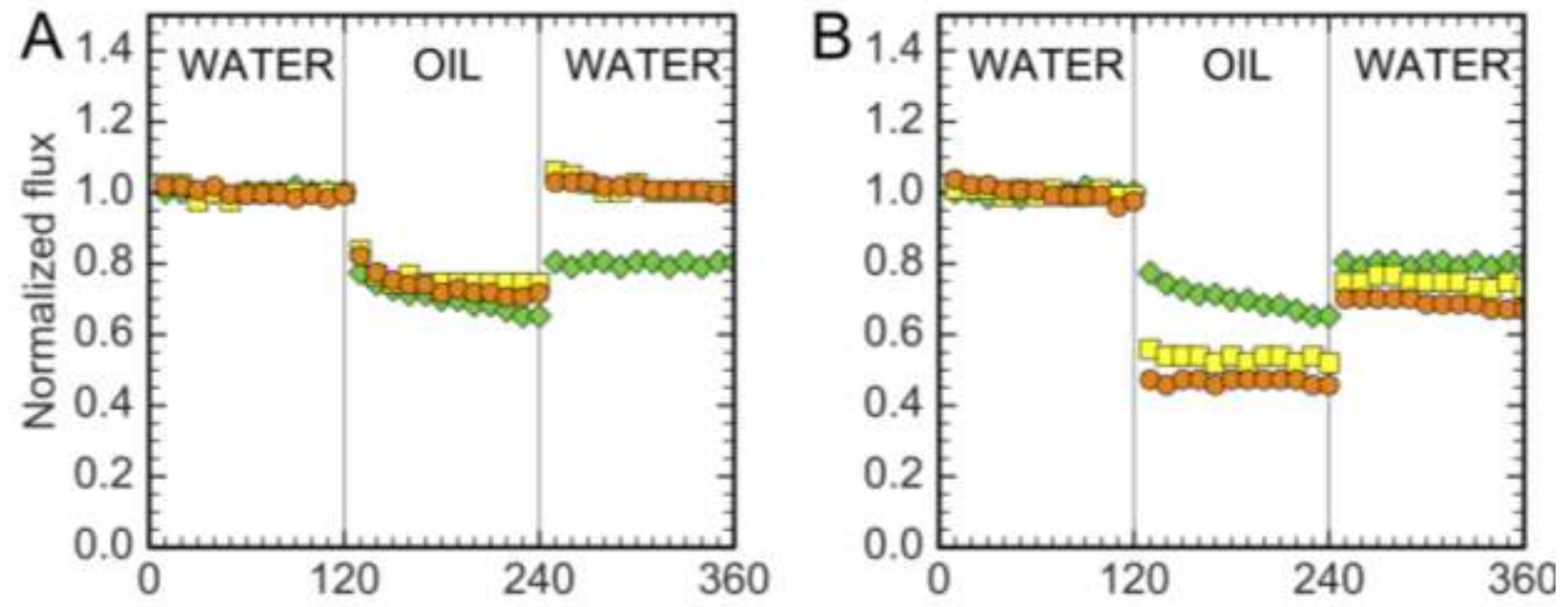

$\diamond$ PV200 $\square \mathrm{M}_{5: 95}-\mathrm{SB} 2 \mathrm{VP} 18 \bullet \mathrm{M}_{10: 90}-\mathrm{SB} 2 \mathrm{VP} 18$

PV200 $\square \mathrm{M}_{5: 95}$-SB2VP51 $\mathrm{M}_{10: 50}$-SB2VP51
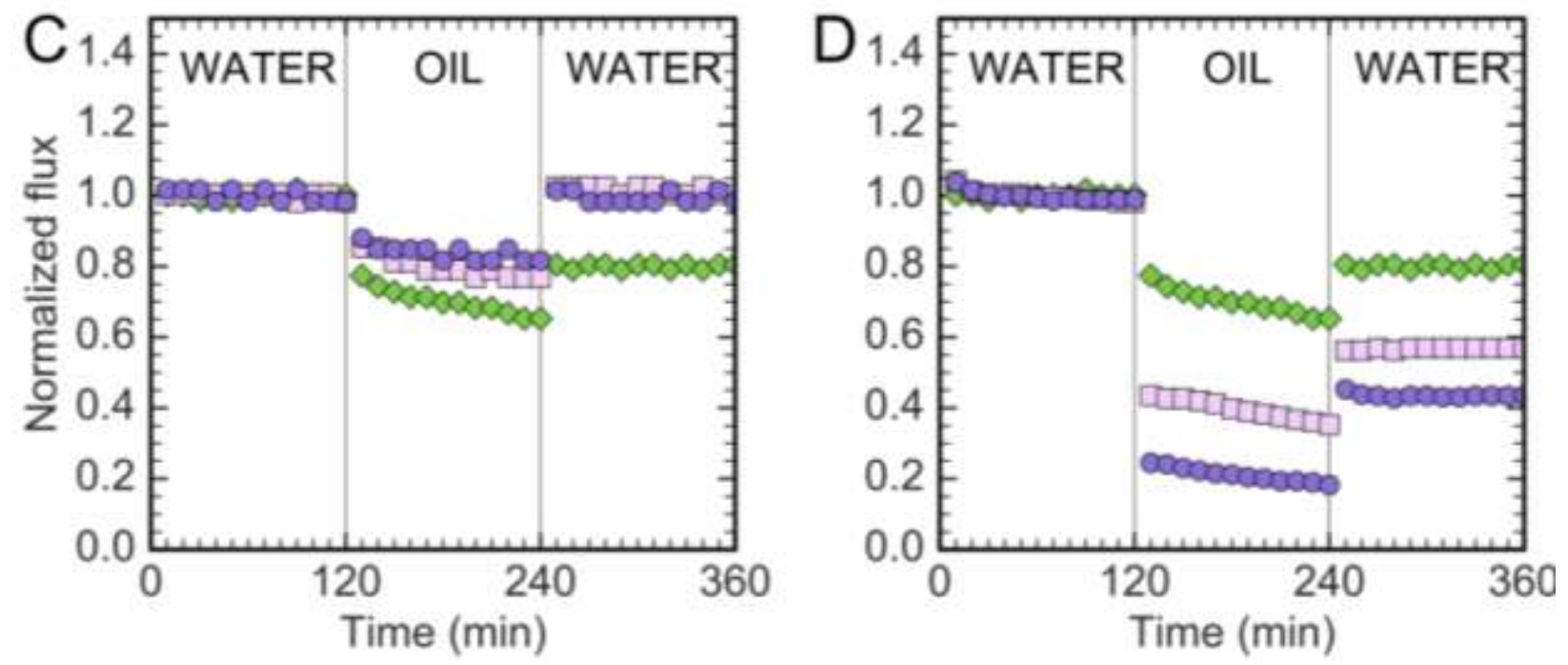

Fig. 6. Short-term oil fouling of (a)M-SBMA19, (b) M-SBMA52, (c) M-SB2VP18, and (d) M-SB2VP51 series membranes along with the commercial control membrane PV200. All fluxes were normalized by the average initial water flux (Table 3 ).

\subsection{Top layer chemical composition of blend membranes}

Short-term oil fouling tests showed a drastic difference between the performances of membranes prepared with low-zwitterion-content additives (M-SBMA19 and M-SB2VP18) and highzwitterion-content additives (M-SBMA52 and M-SB2VP51), regardless of the zwitterion used. The most significant difference was in the extent of irreversible fouling observed. Membranes prepared with additives with $\sim 50 \mathrm{wt} \%$ zwitterionic monomer fouled irreversibly, whereas those with additives containing $\sim 20 \mathrm{wt} \%$ zwiiterionic monomer did not. Previous studies with amphiphilic copolymer membrane additives typically show improved fouling resistance when the hydrophilic content of the additive increases, as long as the additive does not become soluble 
in the casting bath and lost during membrane manufacture and use.[27, 74, 75] The observed results were contrary to these trends.

Propensity for adsorptive fouling is closely related with membrane surface chemistry.[73] Thus, we investigated the differences in the chemical composition of the top layer of membranes prepared with low and high zwitterion content copolymer additives. For this purpose, we performed ATR-FTIR measurements, which characterize the top 0.5-2 $\mu \mathrm{m}$ layer of the membranes. Fig. 7 shows IR spectra obtained from M-SBMA19 and M-SBMA52 series together with the IR spectra of the copolymer additive used and the control M-PVDF. IR spectra of the M-SB2VP18 and M-SB2VP51 series are given in Appendix A, Fig. A.2. The fingerprint O-C=C ester carbonyl stretch at $1740 \mathrm{~cm}^{-1}$ is present only in the additive copolymer and not in the base PVDF. Hence, its detection in IR spectra indicates the presence of the additive copolymers within top 0.5-2 $\mu \mathrm{m}$ of the membrane. In membranes with low-zwitterion-content additives MSBMA19 (Fig. 7a) and M-SB2VP18 (Fig. A.2a), the intensity of the peak at $1740 \mathrm{~cm}^{-1}$ was found to increase proportionally with the increase in zwitterionic copolymer content in casting solution. This finding confirms the presence of zwitterionic copolymer in the top layer of the membrane. The additive copolymer is homogeneously distributed through the thickness of the membrane. In the case of M-SBMA52 (Fig. 7b) and M-SB2VP51 (Fig. A.2b) series, IR spectra showed no peak at this wavenumber. This suggests that the copolymer additive is trapped in the lower regions of the membrane, at least $0.5-2 \mu \mathrm{m}$ below the membrane surface. This likely arises form immiscibility between the copolymer additive and the base PVDF, and the differences in the phase diagrams of PVDF and the copolymers in water/DMSO mixtures. This is also consistent with the SEM cross-sections of these high zwitterion membranes, which showed spherical enclosures of polymer below the membrane surface, confirming poor miscibility between PVDF and the additive copolymer.

It appears that PVDF and the high-zwitterion-content copolymers precipitate at different time points during the membrane formation by NIPS. PVDF has a very low solubility in water, even in the presence of DMSO, so it precipitates out essentially instantaneously at the membrane surface, forming the selective layer. As the copolymer is incompatible with PVDF, and because it has better solubility, it remains in the DMSO-rich solution, being pushed below the membrane surface as the front of non-solvent penetration progresses. At some point, this copolymer precipitates also, but in a separate macrophase than the PVDF. Thus, essentially all the zwitterionic copolymer is trapped in the roughly spherical enclosures observed below the membrane surface. This copolymer is useless for fouling resistance, and only serves to create additional defects in the membrane, leading to the implausibly high water permeance values observed (Table 3). These results imply an upper limit on the zwitterion content of a PMMAbased copolymer for its miscibility with the PVDF and thus successful use as an additive for improving fouling resistance, between $\sim 20 \mathrm{wt} \%$ and $50 \mathrm{wt} \%$. 


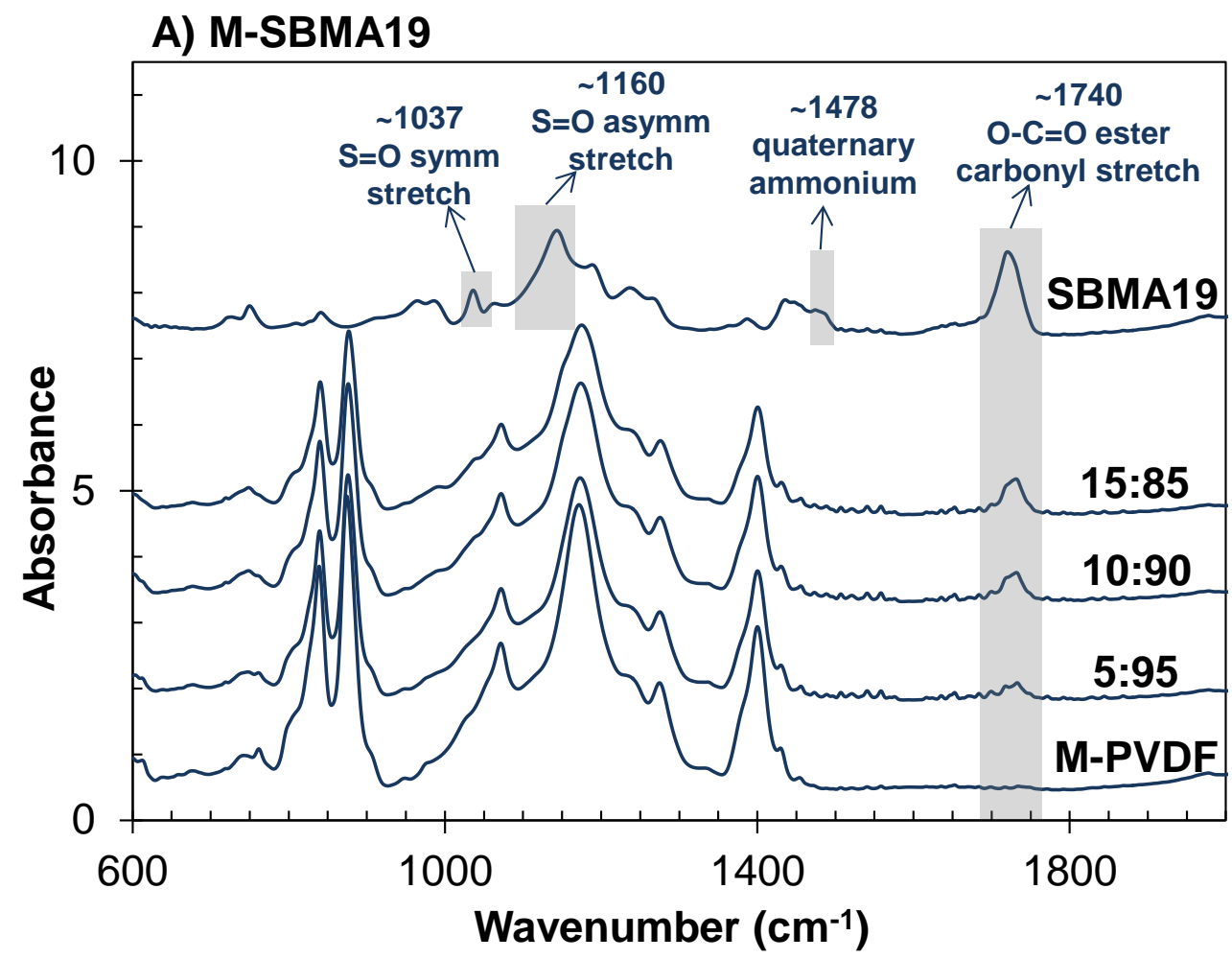

B) M-SBMA52

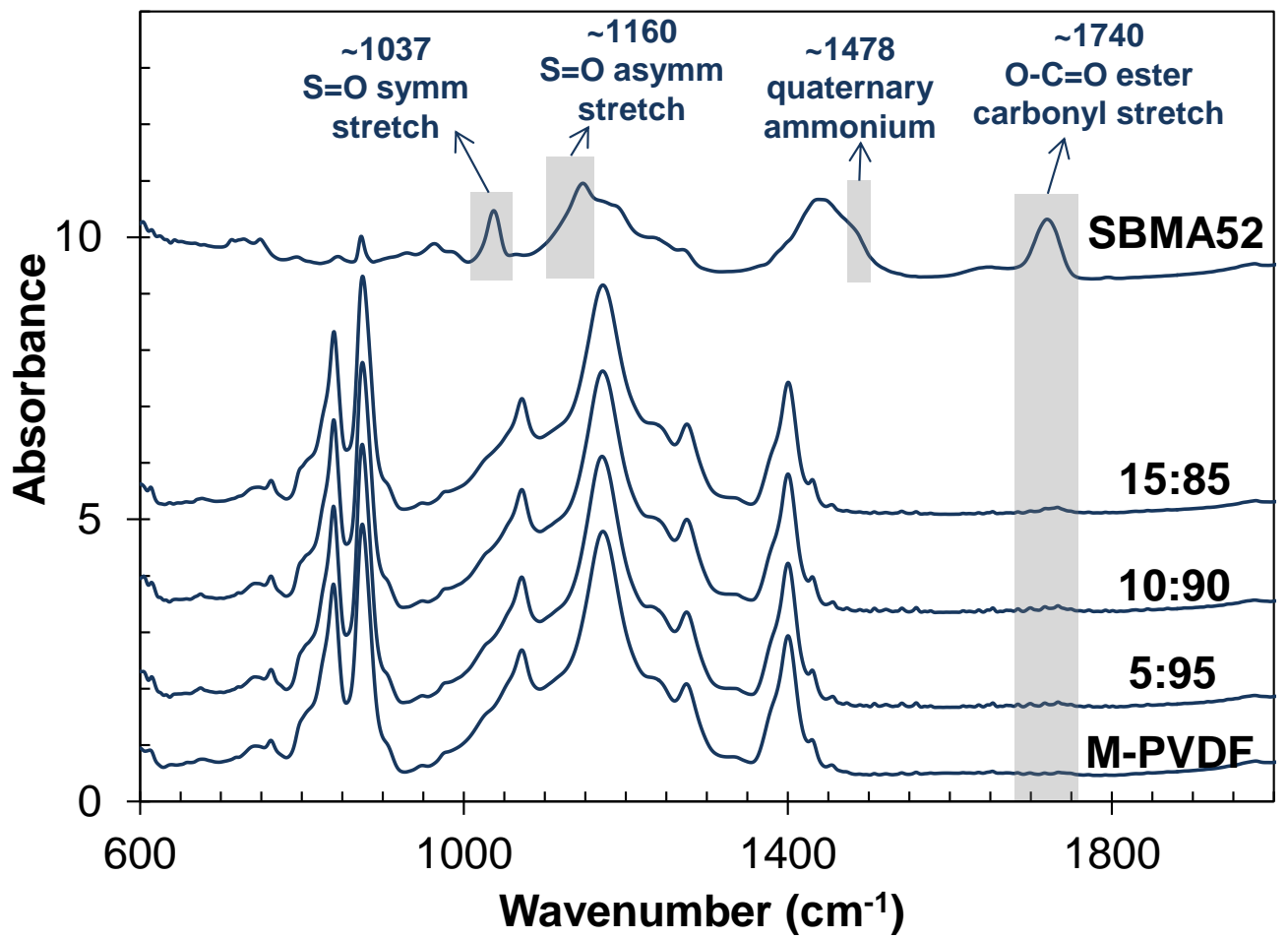

Fig. 7. ATR-FTIR spectra of blend membranes. From bottom to top: (a) M-PVDF, M-SBMA19 series blend membranes, and SBMA19 copolymer, (b) M-PVDF, M-SBMA52 series blend membranes, and SBMA52 copolymer. 


\subsection{Macrophase separation in the blend membranes}

To better charaterize macrophase separation in the PVDF copolymer blends, we utilized thermal analysis using DSC. This method also allowed us to characterize the crystallization of PVDF, which can affect the mechanical properties of the membrane. The most common method to determine the miscibility in blends is following the composition-dependent glass transition temperature $\left(\mathrm{T}_{\mathrm{g}}\right)$. [76] Two separate $\mathrm{T}_{\mathrm{g}}$ 's pertinent to the two components point to a two-phase system, whereas a single $T_{g}$ that changes according to the composition of the blend is deemed a miscibility indicator. $T_{g}$ of a miscible blend can be predicted using the properties of each component. Fig. 8 shows the DSC thermograms of M-SBMA19 and M-SBMA52 membrane series, the zwitterionic additive used in each series, and the control M-PVDF. The thermograms of M-SB2VP18 and M-SB2VP51 membrane series are given in Appendix A, Fig. A.3.
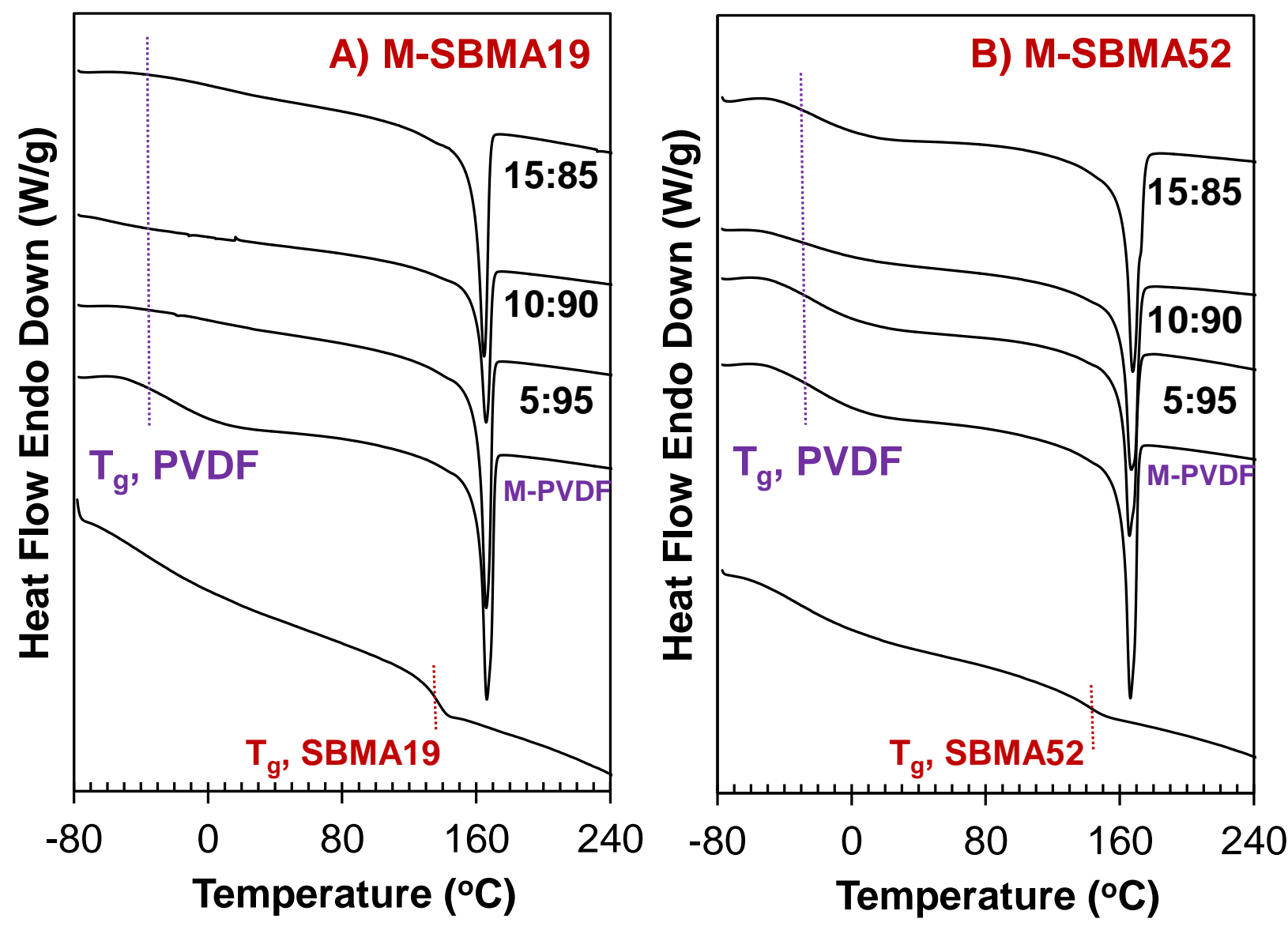

Fig. 8. DSC thermograms of the blend membranes, respective additive copolymer, and M-PVDF. From bottom to top: (a) SBMA19 additive, control M-PVDF, and M-SBMA19 series, (b) SBMA52 additive, control M-PVDF, and M-SBMA52 series. Data acquired during the third step of the heating-coolingheating cycle using $10^{\circ} \mathrm{C} / \mathrm{min}$ heating rate on as-cast, dried membranes.

The $\mathrm{T}_{\mathrm{g}}$ of the control M-PVDF was measured to be $-33{ }^{\circ} \mathrm{C}$, observed as a step change at this temperature, in agreement with literature reposts of the $\mathrm{T}_{g}$ of PVDF polymer.[70] The thermogram for the SBMA19 copolymer shows a $\mathrm{T}_{\mathrm{g}}$ at $137^{\circ} \mathrm{C}$ (Fig. 8a), whereas that for SBMA52 shows a $\mathrm{T}_{\mathrm{g}}$ at $142^{\circ} \mathrm{C}$ (Fig. 8b). The $\mathrm{T}_{\mathrm{g}}$ observed for M-PVDF at $-33^{\circ} \mathrm{C}$ disappears upon 
blending with the additive SBMA19 in thermograms for M-SBMA19 membranes (Fig. 8a). It is challenging to determine the resultant $\mathrm{T}_{\mathrm{g}}$ 's of these blends, though the fact that the $\mathrm{T}_{\mathrm{g}}$ transition softens and shifts indicates the formation of a hybrid phase through the true mixing of PVDF with at least the PMMA segments of this copolymer. In the case of the M-SBMA52 series (Fig. $8 \mathrm{~b}$ ), no change is observed in the $\mathrm{T}_{\mathrm{g}}$ of PVDF with increasing additive content. This confirms poor miscibility between PVDF and the additive copolymer.

Following composition-dependent changes in the crystallization behavior of polymers is another route for determining miscibility in blends.[65, 68, 77] The zwitterionic additive copolymers used in this study are amorphous. To grow crystals, PVDF has to exclude the additive-rich phase, which presumably impedes the crystallization process and decreases crystallinity and $\mathrm{T}_{\mathrm{c}}$. Thus, a gradual decrease in the crystallinity and $\mathrm{T}_{\mathrm{c}}$ of the blends with increasing additive content shows good miscibility between the additive copolymer and PVDF. Fig. 9 shows the DSC crystallization (cooling cycle) thermograms of M-SBMA19 and M-SBMA52 membrane series along with M-PVDF. The crystallization thermograms of M-SB2VP18 and M-SB2VP51 membrane series are given in Appendix A, Fig. A.4. In addition, Table 4 summarizes the thermal properties of all blend membranes obtained using the melting and crystallization curves.
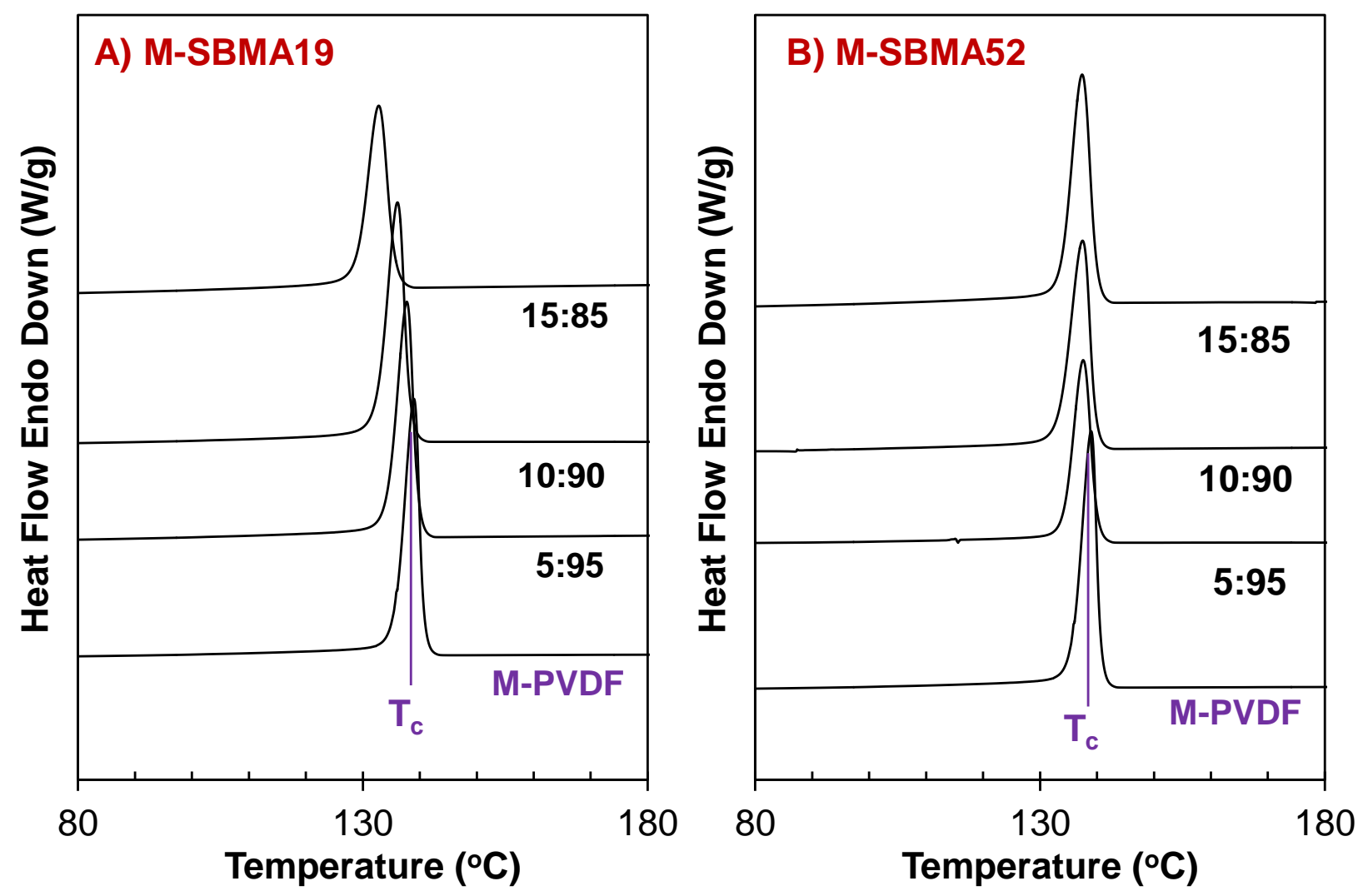

Fig. 9. DSC crystallization thermograms of membranes. From bottom to top: (a) M-PVDF, and MSBMA19 series, (b) M-PVDF, and M-SBMA52 series. Data acquired during the second step of the heating-cooling-heating cycle using $10^{\circ} \mathrm{C} /$ min cooling rate on as-cast, dried membranes. 
Table 4 Thermal properties of membranes studied

\begin{tabular}{|c|c|c|c|c|c|c|c|}
\hline Membrane series & Membrane code & $\begin{array}{l}\mathbf{T}_{\mathbf{m}} \\
\left({ }^{\circ} \mathbf{C}\right)\end{array}$ & $\begin{array}{l}\mathbf{T}_{\mathrm{g}} \\
\left({ }^{\circ} \mathbf{C}\right)\end{array}$ & $\begin{array}{l}\mathbf{T}_{\mathbf{c}} \\
\left({ }^{\circ} \mathbf{C}\right)\end{array}$ & $\begin{array}{l}\Delta \mathbf{H}_{\mathrm{f}} \\
\text { (membrane) } \\
(\mathrm{J} / \mathrm{g})\end{array}$ & $\begin{array}{l}\Delta \mathbf{H}_{\mathbf{f}} \\
(\mathbf{P V D F}) \\
(\mathrm{J} / \mathrm{g})\end{array}$ & $\begin{array}{l}\text { Crystallinity } \\
\text { (PVDF) }\end{array}$ \\
\hline Home-made PVDF & M-PVDF & 166 & -33 & 139 & 59 & 59 & 0.56 \\
\hline \multirow{3}{*}{ M-SBMA19 } & $\mathrm{M}_{5: 95-\mathrm{SBMA19}}$ & 166 & - & 138 & 55 & 58 & 0.55 \\
\hline & $\mathrm{M}_{10: 90-\mathrm{SBMA} 19}$ & 166 & - & 136 & 47 & 52 & 0.50 \\
\hline & $\mathrm{M}_{15: 85-\mathrm{SBMA19}}$ & 165 & - & 133 & 42 & 49 & 0.47 \\
\hline \multirow{3}{*}{ M-SBMA52 } & $\mathrm{M}_{5: 95-\mathrm{SBMA52}}$ & 166 & -33 & 138 & 55 & 58 & 0.55 \\
\hline & $\mathrm{M}_{10: 90-\mathrm{SBMA52}}$ & 166 & -35 & 138 & 54 & 60 & 0.57 \\
\hline & $\mathrm{M}_{15: 85-\mathrm{SBMA52}}$ & 168 & -33 & 140 & 51 & 60 & 0.57 \\
\hline \multirow{3}{*}{ M-SB2VP18 } & $\mathrm{M}_{5: 95-\mathrm{SB} 2 \mathrm{VP} 18}$ & 166 & - & 137 & 56 & 59 & 0.56 \\
\hline & $\mathrm{M}_{10: 90^{-} \mathrm{SB} 2 \mathrm{VP} 18}$ & 165 & - & 135 & 50 & 56 & 0.53 \\
\hline & $\mathrm{M}_{15: 85-\mathrm{SB} 2 \mathrm{VP} 18}$ & 164 & - & 133 & 44 & 52 & 0.50 \\
\hline \multirow{3}{*}{ M-SB2VP51 } & $\mathrm{M}_{5: 95-S B 2 V P 51}$ & 165 & -34 & 137 & 56 & 59 & 0.56 \\
\hline & $\mathrm{M}_{10: 90-\mathrm{SB} 2 \mathrm{VP} 51}$ & 166 & -34 & 136 & 53 & 59 & 0.56 \\
\hline & $\mathrm{M}_{15: 85-\mathrm{SB} 2 \mathrm{VP} 51}$ & 165 & -33 & 136 & 51 & 60 & 0.57 \\
\hline
\end{tabular}

The $\mathrm{T}_{\mathrm{c}}$ of M-SBMA19 series blend membranes gradually decreases with increasing additive content, conforming to previously shown good miscibility between PVDF and SBMA19. In the M-SBMA52 series, a slight decrease in the $T_{c}$ of PVDF is observed upon blending with SBMA52 at the 5:95 additive:PVDF ratio, but there is no further systematic change in $\mathrm{T}_{\mathrm{c}}$ with increasing additive content, as expected from the macro-phase separated structure. The initial decrease in $\mathrm{T}_{\mathrm{c}}$ suggests that the non-miscible component may be acting as a nucleating agent in the crystallization process of PVDF. Similar results are obtained from the M-SB2VP18 and MSB2VP51 series (Table 4 and Appendix A, Fig. A.4).

The crystallinity of PVDF also undergoes changes. Table 4 shows the heat of fusion $\left(\Delta \mathrm{H}_{\mathrm{f}}\right)$ measured directly from the DSC melting thermograms. The $\Delta \mathrm{H}_{\mathrm{f}}$ measured for the PVDF domains in the copolymer (Column 7) was obtained by dividing the total $\Delta \mathrm{H}_{\mathrm{f}}$ (sixth column) by the weight fraction of PVDF in the membrane. The last column represents the degree of crystallinity of PVDF in the membrane, calculated by dividing the $\Delta \mathrm{H}_{\mathrm{f}}$ of PVDF domains by the value for perfect PVDF crystal $\left(\Delta \mathrm{H}^{0}=105 \mathrm{~J} / \mathrm{g}\right)$ obtained from past study.[78] The crystallinity of M-PVDF membrane is approximately $56 \%$, in the typical range for PVDF films.[79, 80] In the M-SBMA19 and M-SB2VP18 series, prepared with low-zwitterion-content copolymers, crystallinity drops gradually with increasing additive content, once again showing good miscibility between the two polymers. As expected, M-SBMA52 and M-SB2VP51 series do not show any systematic change in their crystallinity. These findings are in accordance with the immiscibility of the two polymers in membrane series prepared with additives with high zwitterion contents, M-SBMA52 and M-SB2VP51, observed previously by the SEM, FTIR and DSC melting studies.

It should be noted that these thermal analyses can potentially be performed without the need for membrane manufacture or testing, to predict if the copolymer additive of interest will be miscible with the base polymer of interest. Only a few mg of each polymer is needed to run these DSC analyses, and to predict if a proposed copolymer additive will exhibit miscibility issues that 
negatively impact membrane performance as those observed with SBMA52 and SB2VP51. This means that DSC can be utilized as a predictive screening process for identifying copolymer additive compositions for this application, enabling researchers and manufacturers to screen a large number of proposed compositions without the need for tedious membrane manufacture and testing.

\subsection{Long-term fouling resistance against oil}

Results obtained so far in this study proved that membranes prepared with copolymers with $\sim 20$ wt\% zwitterion content, M-SBMA19 and M-SB2VP18 series, perform significantly better for several reasons compared to their high zwitterion counterparts, M-SBMA52 and M-SB2VP51 series. To better characterize the fouling resistance and filtration performance of these more promising membrane formulations, membranes of the series M-SBMA19 and M-SB2VP18 with additive:PVDF ratio 10:90 were chosen for long-term oil fouling tests due to their high fluxes and similar BSA rejection to that of those with additive:PVDF ratio 5:95. Fig. 10 shows the change in normalized flux with time for a 24 hour dead-end filtration of oil-in-water emulsion for both blend membranes along with control M-PVDF membrane. At the end of 24 hour oil-inwater emulsion filtration, the normalized flux of the $\mathrm{M}_{10: 90-S B M A 19}$ and $\mathrm{M}_{10: 90-S B 2 V P 18}$ membranes were reduced to $44 \%$ and $53 \%$ of the initial value, respectively. The flux of MPVDF decreased to $58 \%$ of its initial flux. Upon switching to pure water after storage in DI water overnight, the $\mathrm{M}_{10: 90^{-}}$SBMA19 membrane recovered $93 \%$ of its initial flux. The $\mathrm{M}_{10: 90^{-}}$ SB2VP18 membrane recovered its initial flux completely, proving excellent resistance against oil fouling. On the other hand, the M-PVDF lost $25 \%$ of its initial flux permanently due to irreversible oil fouling despite the fact that a lower amount of oily water was filtered through this membrane $(216 \mathrm{~mL})$ during the experiment in comparison with the zwitterion-containing membranes (634 $\mathrm{mL}$ and $627 \mathrm{~mL}$ for $\mathrm{M}_{10: 90}$-SBMA19 and $\mathrm{M}_{10: 90}$-SB2VP18, respectively) due to its lower initial water flux.

To date, there has been one study only, which shows the use of surface segregating zwitterionic additives to develop antifouling PVDF membrane for separation of oil/water emulsion. [52] In this case, the best performing membrane featured a flux $\left(90 \mathrm{~L} / \mathrm{m}^{2} . h\right)$ lower than those of $\mathrm{M}_{10: 90^{-}}$ SBMA19 and M10:90-SB2VP18 membranes, with pore size ranging in $20 \mathrm{~nm}-100 \mathrm{~nm}$. These membranes showed excellent antifouling performance against both protein and oil fouling. However, oil/water emulsion was filtered for $1 \mathrm{~h}$ periods only in three cycles, challenging the membranes far less than our continuous $24 \mathrm{~h}$ oil/water emulsion filtration. Our results demonstrate that only $10 \%$ of a zwitterionic additive with respect to PVDF can yield essentially complete resistance to irreversible fouling in long term and much higher flux, but only if the zwitterionic copolymer is designed carefully to prevent macrophase separation during membrane formation. 


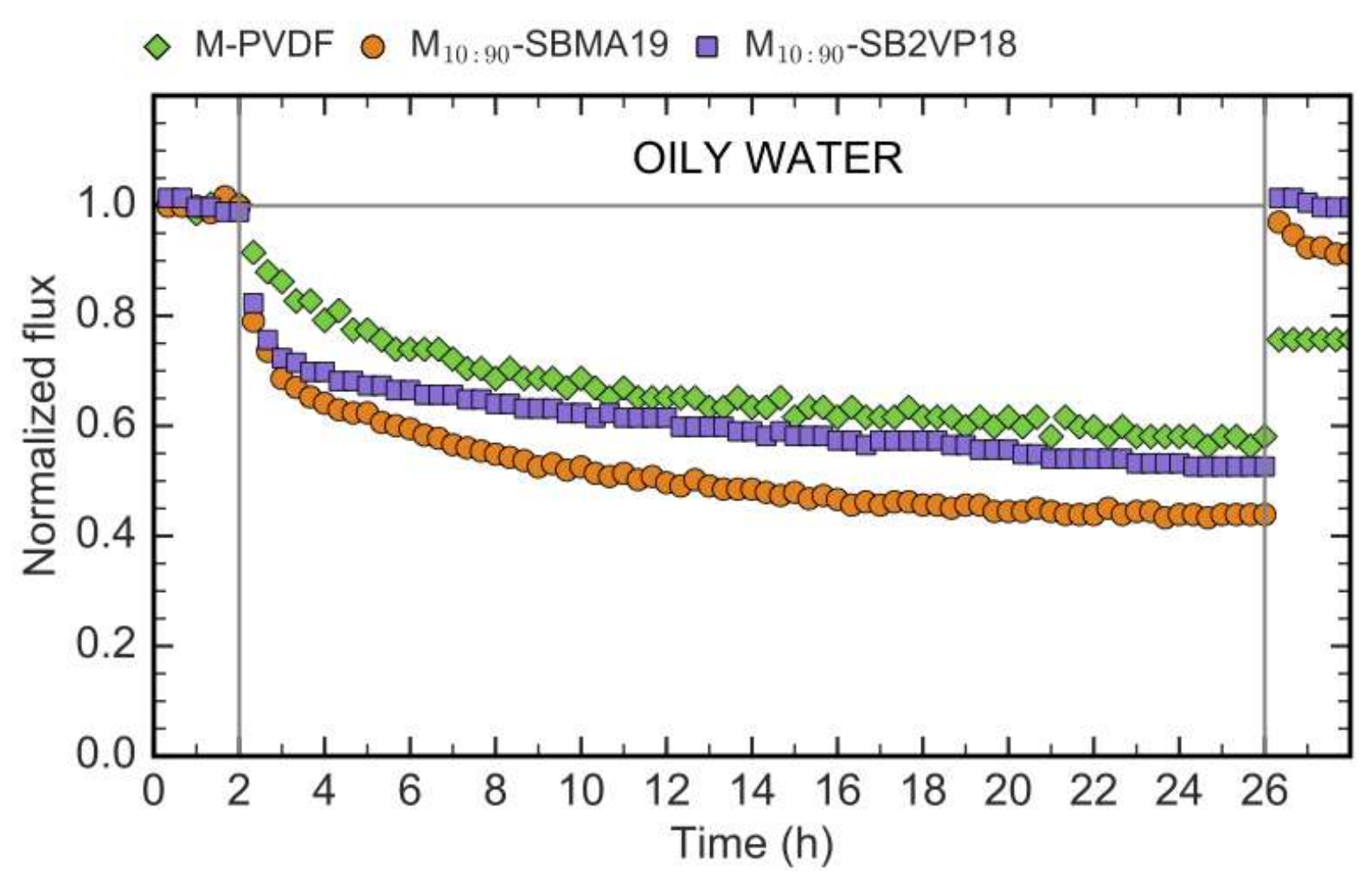

Fig. 10. Long-term fouling resistance against oil for $\mathrm{M}_{10: 90-S B M A 19,} \mathrm{M}_{10: 90}-\mathrm{SB} 2 \mathrm{VP} 18$ and $\mathrm{M}$ PVDF membranes. All fluxes were normalized by the average initial water flux (Table 3).

\subsection{Long-term fouling resistance against proteins}

Proteins are another class of common foulants found in wastewater streams and in other critical UF applications such as bioseparations and food and beverage industries.[81, 82] They tend to adsorb on membrane surfaces and pore walls, blocking pores and preventing permeation. To characterize the fouling resistance of the promising M-SBMA19 and M-SB2VP18 membranes to a wider range of foulants, we tested their resistance to fouling by proteins. To determine the short-term fouling resistance, $2 \mathrm{~h}$ dead-end filtration tests were conducted using $1 \mathrm{~g} / \mathrm{L}$ solution of BSA in PBS as the foulant feed. BSA rejection of $\mathrm{M}_{5: 95}$-SBMA19 and $\mathrm{M}_{10: 90}$-SBMA19 membranes were both found to be $99 \%$, whereas that $\mathrm{M}_{5: 95}-\mathrm{SB} 2 \mathrm{VP} 18$ and $\mathrm{M}_{10: 90-\mathrm{SB} 2 \mathrm{VP} 18}$ membranes were $93 \%$ and $86 \%$, respectively (Table 3). Table A.4 in Appendix A reports the initial water permeance, final BSA solution permeance, water permeance after PBS solution rinse, and total BSA solution filtered through the membrane, obtained from $2 \mathrm{~h}$ dead-end BSA filtration tests on M-SBMA19 and M-SB2VP18 series. In these short term BSA fouling tests, all four blend membranes prepared with $\sim 20 \mathrm{wt} \%$ zwitterion-containing copolymer additives could recover their initial flux completely upon switching to pure water after a PBS rinse, showing complete resistance against irreversible protein fouling. After similar treatment, the commercial control PV200 membrane lost $25 \%$ of its initial flux due to irreversible fouling.

Among the membranes in M-SBMA19 and M-SB2VP18 series, those with additive:PVDF ratio 10:90 were chosen for long-term protein fouling tests due to their higher fluxes. In long-term protein fouling tests, the dead-end filtration tests were conducted for $24 \mathrm{~h}$ using $1 \mathrm{~g} / \mathrm{L} \mathrm{BSA}$ in PBS as the foulant solution. The M-PVDF membrane was used as a control. The results of these 
filtration runs are shown in Fig. 11. After $24 \mathrm{~h}$ of protein filtration, the flux declined to 25-35\% of the initial flux for both blend membranes investigated. Flux through the control M-PVDF membrane was reduced to $36 \%$ of its initial value. Upon switching to pure water after overnight storage in PBS, the control M-PVDF membrane lost $40 \%$ of its initial flux due to irreversible fouling. In contrast, both $\mathrm{M}_{10: 90}$-SBMA19 and $\mathrm{M}_{10: 90}$-SB2VP18 membranes recovered their initial fluxes completely to values within the error margin for measuring the permeance. This indicates that these two membrane formulations resist irreversible protein fouling essentially completely. It should also be mentioned that the amount of BSA solution filtered through the control M-PVDF membrane $(149 \mathrm{~mL})$ was much lower than the amount filtered through the zwitterion-containing membranes $\left(509 \mathrm{~mL}\right.$ and $513 \mathrm{~mL}$ for $\mathrm{M}_{10: 90^{-}}$SBMA19 and $\mathrm{M}_{10: 90^{-}}$ SB2VP18, respectively).

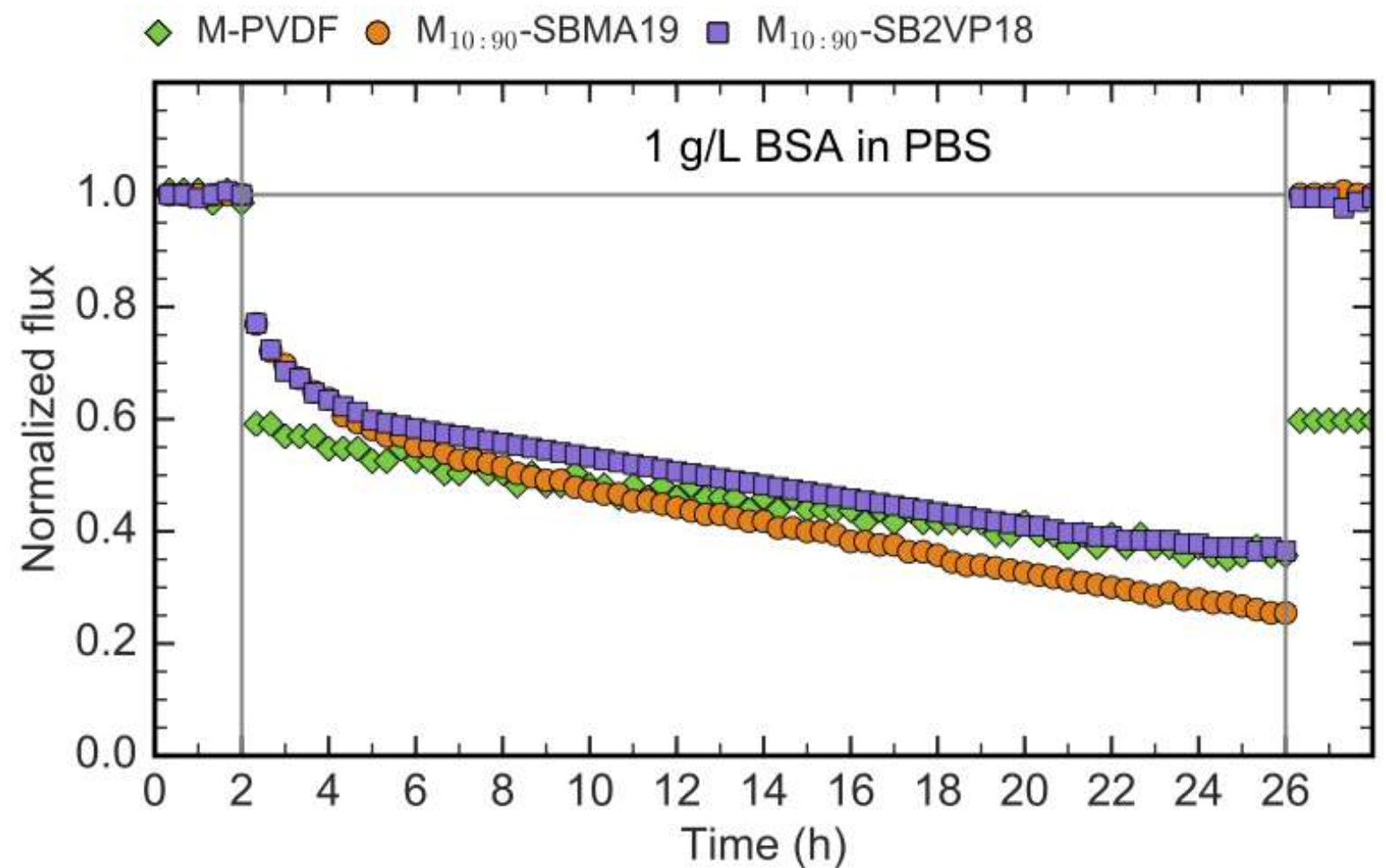

Fig. 11. Long-term fouling resistance against BSA of $M_{10: 90-S B M A 19,} M_{10: 90}-S B 2 V P 18$ and MPVDF membranes. All fluxes were normalized by the average initial water flux (Table 3).

Past studies that involve the use of surface segregating zwitterionic additives in blend UF membranes have also shown promising results in terms of improvement in flux, selectivity and protein fouling resistance. Blend UF membranes containing zwitterionic additives, with BSA rejections similar to those of $\mathrm{M}_{10: 90}$-SBMA19 and $\mathrm{M}_{10: 90-S B 2 V P 18}$ membranes and higher flux, have been reported to exhibit very strong BSA fouling resistance as well.[43, 83] However, these results were often obtained from short-term BSA runs, where the most compelling treatment was 2h BSA runs of three cycles.[43] It should be mentioned that an amphiphilic copolymer additive, PVDF- $g$-PSBMA, has been used to improve the antifouling ability of PVDF membranes.[46] Despite the high fluxes (over $200 \mathrm{~L} / \mathrm{m}^{2} . h$ ), membranes lost almost $20 \%$ of their permeability in a single BSA run of $100 \mathrm{~min}$, and the BSA rejections were not reported. Evidently, so far there has 
been no study like ours, which shows excellent BSA fouling resistance following a BSA filtration run as long as $24 \mathrm{~h}$.

\subsection{Chemical and mechanical stability of the membranes}

The chemical stability of the high performing $\mathrm{M}_{10: 90}$-SBMA19 and $\mathrm{M}_{10: 90}$-SB2VP18 membranes was determined by analyzing the water flux and chemical composition by ATR-FTIR, before and after storing the membranes in $0.1 \mathrm{M} \mathrm{NaOH}$ solution for 14 days. No change was observed in the water flux or chemical composition of the membranes (Appendix A, Fig. A.5) after the treatment.

The mechanical stability of the $\mathrm{M}_{10: 90-S B M A 19}$ and $\mathrm{M}_{10: 90}$-SB2VP18 membranes was characterized by measuring the burst pressure. The water filtration pressure was increased gradually in $10 \mathrm{psi}(0.07 \mathrm{MPa})$ increments, from $10 \mathrm{psi}(0.07 \mathrm{MPa})$ to $50 \mathrm{psi}(0.35 \mathrm{MPa})$. An abrupt increase in water permeance was observed at the burst pressure, measured to be 40 psi (0.28 MPa) and $45 \mathrm{psi}(0.31 \mathrm{MPa})$ for $\mathrm{M}_{10: 90}$-SBMA19 and $\mathrm{M}_{10: 90}$-SB2VP18, respectively.

\section{Conclusion}

In this study, we determined the impact of different copolymer properties such as zwitterion chemistry, copolymer composition (i.e. zwitterionic/hydrophobic monomer ratio), and blend composition on resulting membranes features, and thus membrane performance and fouling resistance. We analyzed the morphology, selectivity, permeance and fouling resistance of the blend membranes prepared by changing these variables. We found that, in contrast to previous literature, $[27,74,75]$ increasing the hydrophilic/zwitterionic monomer amount in the additive copolymer does not always improve the membrane performance. Instead, high zwitterion content in the copolymer additive actuates macrophase separation from the base PVDF during membrane formation by NIPS, and the produced blend membrane has low performance. These miscibility issues can be predicted using thermal analysis of PVDF/copolymer blends using only a few mg of sample, without the need for membrane manufacture or time consuming filtration tests. We also demonstrated that, with the appropriate conditions, membranes with high permeance and strong fouling resistance could be obtained even with very little amount of zwitterionic additive used. Zwitterionic additive content as little as $5 \mathrm{wt} \%$ in PVDF can lead to membranes with doubled water flux and complete fouling resistance against both proteins and oil. Past studies using amphiphilic copolymer additives only showed comparable fouling resistance when a minimum of $20 \mathrm{wt} \%$ copolymer additive was used, as smaller quantities did not lead to sufficient surface coverage with fouling resistant groups.[27, 74, 75] This information is crucial for actuating suitable design of zwitterion-containing polymers in membrane applications, and developing fouling resistant UF membranes with copolymer additives to be deployed in industrial and domestic wastewater treatment facilities and biomanufacturing processes.

\section{Acknowledgements}

The authors thank David Wilbur for help with NMR analysis, and Prof. Peggy Cebe for access to the thermal analysis facilities and useful discussions. This research was funded by Tufts Institute of the Environment Fellowship and the National Science Foundation (NSF) under Grants no. CBET-1437772 and CHE-1508049. 


\section{References}

[1] R. Singh, N. Hankins, Emerging Membrane Technology for Sustainable Water Treatment, Elsevier, 2016.

[2] R.W. Baker, Membrane Technology and Applications, second ed., J. Wiley, Chichester, New York, 2004.

[3] M. Khayet, T. Matsuura, Preparation and characterization of polyvinylidene fluoride membranes for membrane distillation, Ind. Eng. Chem. Res., 40 (2001) 5710-5718.

[4] M. Khayet, C. Feng, K. Khulbe, T. Matsuura, Study on the effect of a non-solvent additive on the morphology and performance of ultrafiltration hollow-fiber membranes, Desalination, 148 (2002) 321-327.

[5] S. Chabot, C. Roy, G. Chowdhury, T. Matsuura, Development of poly (vinylidene fluoride) hollow - fiber membranes for the treatment of water/organic vapor mixtures, J. Appl. Polym. Sci., 65 (1997) 1263-1270.

[6] W. Benzinger, B. Parekh, J. Eichelberger, High temperature ultrafiltration with Kynar® poly (vinylidene fluoride) membranes, Sep. Sci. Technol., 15 (1980) 1193-1204.

[7] X. Cao, J. Ma, X. Shi, Z. Ren, Effect of TiO2 nanoparticle size on the performance of PVDF membrane, Appl. Surf. Sci., 253 (2006) 2003-2010.

[8] J. Busch, A. Cruse, W. Marquardt, Modeling submerged hollow-fiber membrane filtration for wastewater treatment, J. Membr. Sci. , 288 (2007) 94-111.

[9] C.-H. Lu, W.-H. Wu, R.B. Kale, Microemulsion-mediated hydrothermal synthesis of photocatalytic TiO2 powders, J. Hazard. Mater., 154 (2008) 649-654.

[10] M.L. Hami, M. Al-Hashimi, M. Al-Doori, Effect of activated carbon on BOD and COD removal in a dissolved air flotation unit treating refinery wastewater, Desalination, 216 (2007) 116-122.

[11] M.F.A. Goosen, S.S. Sablani, H. Ai-Hinai, S. Ai-Obeidani, R. Al-Belushi, D. Jackson, Fouling of reverse osmosis and ultrafiltration membranes: A critical review, Sep. Sci. Technol., 39 (2004) 2261-2297.

[12] J.S. Baker, L.Y. Dudley, Biofouling in membrane systems - a review, Desalination, 118 (1998) 81-90.

[13] J.F. Jhong, A. Venault, C.C. Hou, S.H. Chen, T.C. Wei, J. Zheng, J. Huang, Y. Chang, Surface zwitterionization of expanded poly(tetrafluoroethylene) membranes via atmospheric plasma-induced polymerization for enhanced skin wound healing, ACS Appl. Mater. Interfaces, 5 (2013) 6732-6742.

[14] H.J. Yu, Y.M. Cao, G.D. Kang, J.H. Liu, M. Li, Q. Yuan, Enhancing antifouling property of polysulfone ultrafiltration membrane by grafting zwitterionic copolymer via UV-initiated polymerization, J. Membr. Sci., 342 (2009) 6-13.

[15] A. Bhattacharya, B.N. Misra, Grafting: a versatile means to modify polymers - Techniques, factors and applications, Prog. Polym. Sci., 29 (2004) 767-814.

[16] K.B. Jirage, C.R. Martin, New developments in membrane-based separations, Trends Biotechnol., 17 (1999) 197-200.

[17] F. Poncin-Epaillard, G. Legeay, Surface engineering of biomaterials with plasma techniques, J. Biomater. Sci., Polym. Ed., 14 (2003) 1005-1028.

[18] R. Revanur, K. Kratz, K. Breitenkamp, B.D. McCloskey, B.D. Freeman, T.S. Emrick, Graft copolymer coatings to prevent membrane fouling, in: Abstr Pap Am Chem S, 2009. 
[19] R. Yang, K.K. Gleason, Ultrathin antifouling coatings with stable surface zwitterionic functionality by initiated Chemical Vapor Deposition (iCVD), Langmuir, 28 (2012) 1226612274.

[20] R. Yang, J.J. Xu, G. Ozaydin-Ince, S.Y. Wong, K.K. Gleason, Surface-tethered zwitterionic ultrathin antifouling coatings on reverse osmosis membranes by initiated chemical vapor deposition, Chem. Mater., 23 (2011) 1263-1272.

[21] K. Kratz, W. Xie, A. Lee, B.D. Freeman, T. Emrick, Phosphorylcholine-substituted ROMP polyolefin coatings provide fouling resistance to membrane materials, Macromol. Mater. Eng., 296 (2011) 1142-1148.

[22] R. Yang, A. Asatekin, K.K. Gleason, Design of conformal, substrate-independent surface modification for controlled protein adsorption by chemical vapor deposition (CVD), Soft Matter, 8 (2012) 31-43.

[23] P. Kaner, D.J. Johnson, E. Seker, N. Hilal, S.A. Altinkaya, Layer-by-layer surface modification of polyethersulfone membranes using polyelectrolytes and $\mathrm{AgCl} / \mathrm{TiO} 2$ xerogels, J. Membr. Sci., 493 (2015) 807-819.

[24] J.F. Hester, P. Banerjee, A.M. Mayes, Preparation of protein-resistant surfaces on poly(vinylidene fluoride) membranes via surface segregation, Macromolecules, 32 (1999) 16431650.

[25] J.F. Hester, P. Banerjee, Y.Y. Won, A. Akthakul, M.H. Acar, A.M. Mayes, ATRP of amphiphilic graft copolymers based on PVDF and their use as membrane additives, Macromolecules, 35 (2002) 7652-7661.

[26] J.F. Hester, A.M. Mayes, Design and performance of foul-resistant poly(vinylidene fluoride) membranes prepared in a single-step by surface segregation, J. Membr. Sci. , 202 (2002) 119-135.

[27] A. Asatekin, S. Kang, M. Elimelech, A.M. Mayes, Anti-fouling ultrafiltration membranes containing polyacrylonitrile-graft-poly(ethylene oxide) as an additive, J. Membr. Sci. , 298 (2007) 136-146.

[28] B. Jung, Preparation of hydrophilic polyacrylonitrile blend membranes for ultrafiltration, J. Membr. Sci., 229 (2004) 129-136.

[29] J.Y. Park, M.H. Acar, A. Akthakul, W. Kuhlman, A.M. Mayes, Polysulfone-graftpoly(ethylene glycol) graft copolymers for surface modification of polysulfone membranes, Biomaterials, 27 (2006) 856-865.

[30] S. Kang, A. Asatekin, A.M. Mayes, M. Elimelech, Protein antifouling mechanisms of PAN UF membranes incorporating PAN-g-PEO additive, J. Membr. Sci., 296 (2007) 42-50.

[31] C.L. Lv, Y.L. Su, Y.Q. Wang, X.L. Ma, Q. Sun, Z.Y. Jiang, Enhanced permeation performance of cellulose acetate ultrafiltration membrane by incorporation of Pluronic F127, J. Membr. Sci., 294 (2007) 68-74.

[32] P. Kaner, P. Bengani-Lutz, I. Sadeghi, A. Asatekin, Responsive filtration membranes by polymer self-assembly, Technology, 4 (2016) 1-12.

[33] G.S. Georgiev, E.B. Karnenska, E.D. Vassileva, I.P. Kamenova, V.T. Georgieva, S.B. Iliev, I.A. Ivanov, Self-assembly, anti polyelectrolyte effect, and nonbiofouling properties of polyzwitterions, Biomacromolecules, 7 (2006) 1329-1334.

[34] Q. Li, Q.Y. Bi, B. Zhou, X.L. Wang, Zwitterionic sulfobetaine-grafted poly(vinylidene fluoride) membrane surface with stably anti-protein-fouling performance via a two-step surface polymerization, Appl. Surf. Sci., 258 (2012) 4707-4717. 
[35] Q. Li, B. Zhou, Q.-Y. Bi, X.-L. Wang, Surface modification of PVDF membranes with sulfobetaine polymers for a stably anti-protein-fouling performance, J. Appl. Polym. Sci., 125 (2012) 4015-4027.

[36] Y. Liu, S.L. Zhang, G.B. Wang, The preparation of antifouling ultrafiltration membrane by surface grafting zwitterionic polymer onto poly(arylene ether sulfone) containing hydroxyl groups membrane, Desalination, 316 (2013) 127-136.

[37] W.W. Yue, H.J. Li, T. Xiang, H. Qin, S.D. Sun, C.S. Zhao, Grafting of zwitterion from polysulfone membrane via surface-initiated ATRP with enhanced antifouling property and biocompatibility, J. Membr. Sci., 446 (2013) 79-91.

[38] G. Zhai, S.C. Toh, W.L. Tan, E.T. Kang, K.G. Neoh, C.C. Huang, D.J. Liaw, Poly(vinylidene fluoride) with grafted zwitterionic polymer side chains for electrolyteresponsive microfiltration membranes, Langmuir, 19 (2003) 7030-7037.

[39] Y.-H. Zhao, K.-H. Wee, R. Bai, A novel electrolyte-responsive membrane with tunable permeation selectivity for protein purification, ACS Appl. Mater. Interfaces 2(2009) 203-211.

[40] A. Asatekin, A.M. Mayes, Oil industry wastewater treatment with fouling resistant membranes containing amphiphilic comb copolymers, Environ. Sci. Technol., 43 (2009) 44874492.

[41] A. Adout, S. Kang, A. Asatekin, A.M. Mayes, M. Elimelech, Ultrafiltration membranes incorporating amphiphilic comb copolymer additives prevent irreversible adhesion of bacteria, Environ. Sci. Technol., 44 (2010) 2406-2411.

[42] Y.L. Su, L.L. Zheng, C. Li, Z.Y. Jiang, Smart zwitterionic membranes with on/off behavior for protein transport, J. Phys. Chem. B, 112 (2008) 11923-11928.

[43] Q. Sun, Y. Su, X. Ma, Y. Wang, Z. Jiang, Improved antifouling property of zwitterionic ultrafiltration membrane composed of acrylonitrile and sulfobetaine copolymer, J. Membr. Sci., 285 (2006) 299-305.

[44] L. Wang, Y.-1. Su, L. Zheng, W. Chen, Z. Jiang, Highly efficient antifouling ultrafiltration membranes incorporating zwitterionic poly ([3-(methacryloylamino) propyl]-dimethyl (3sulfopropyl) ammonium hydroxide), J. Membr. Sci., 340 (2009) 164-170.

[45] X.J. Huang, Z.K. Xu, L.S. Wan, Z.G. Wang, J.L. Wang, Novel acrylonitrile-based copolymers containing phospholipid moieties: Synthesis and characterization, Macromol. Biosci., 5 (2005) 322-330.

[46] J.-H. Li, M.-Z. Li, J. Miao, J.-B. Wang, X.-S. Shao, Q.-Q. Zhang, Improved surface property of PVDF membrane with amphiphilic zwitterionic copolymer as membrane additive, Appl. Surf. Sci., 258 (2012) 6398-6405.

[47] Q. Shi, Y. Su, W. Zhao, C. Li, Y. Hu, Z. Jiang, S. Zhu, Zwitterionic polyethersulfone ultrafiltration membrane with superior antifouling property, J. Membr. Sci., 319 (2008) 271-278.

[48] T. Wang, Y.-Q. Wang, Y.-L. Su, Z.-Y. Jiang, Antifouling ultrafiltration membrane composed of polyethersulfone and sulfobetaine copolymer, J. Membr. Sci., 280 (2006) 343-350.

[49] S. Rajabzadeh, D. Ogawa, Y. Ohmukai, Z. Zhou, T. Ishigami, H. Matsuyama, Preparation of a PVDF hollow fiber blend membrane via thermally induced phase separation (TIPS) method using new synthesized zwitterionic copolymer, Desalin. Water Treat., 54 (2015) 2911-2919.

[50] K. Tu, P. Shen, J. Li, B. Fan, C. Yang, R. Du, Preparation of enduringly antifouling PVDF membrane with compatible zwitterionic copolymer via thermally induced phase separation, J. Appl. Polym. Sci., 132 (2015). 
[51] Z. Yi, L.-P. Zhu, H. Zhang, B.-K. Zhu, Y.-Y. Xu, Ionic liquids as co-solvents for zwitterionic copolymers and the preparation of poly (vinylidene fluoride) blend membranes with dominated $\beta$-phase crystals, Polymer, 55 (2014) 2688-2696.

[52] X. Zhao, W. Chen, Y. Su, W. Zhu, J. Peng, Z. Jiang, L. Kong, Y. Li, J. Liu, Hierarchically engineered membrane surfaces with superior antifouling and self-cleaning properties, J. Membr. Sci., 441 (2013) 93-101.

[53] P. Bengani, Y. Kou, A. Asatekin, Zwitterionic copolymer self-assembly for fouling resistant, high flux membranes with size-based small molecule selectivity, J. Membr. Sci. , 493 (2015) 755-765.

[54] C. Huang, L. Zhang, Miscibility of poly (vinylidene fluoride) and atactic poly (methyl methacrylate), J. Appl. Polym. Sci., 92 (2004) 1-5.

[55] H. Tomura, H. Saito, T. Inoue, Light scattering analysis of upper critical solution temperature behavior in a poly (vinylidene fluoride)/poly (methyl methacrylate) blend, Macromolecules, 25 (1992) 1611-1614.

[56] P.K. Singh, V.K. Singh, M. Singh, Zwitterionic polyelectrolytes: A review, e-Polym., 30 (2007) 1-34.

[57] Q. Sun, Y.L. Su, X.L. Ma, Y.Q. Wang, Z.Y. Jiang, Improved antifouling property of zwitterionic ultrafiltration membrane composed of acrylonitrile and sulfobetaine copolymer, J. Membr. Sci., 285 (2006) 299-305.

[58] P.-F. Ren, Y. Fang, L.-S. Wan, X.-Y. Ye, Z.-K. Xu, Surface modification of polypropylene microfiltration membrane by grafting poly (sulfobetaine methacrylate) and poly (ethylene glycol): Oxidative stability and antifouling capability, J. Membr. Sci., 492 (2015) 249-256.

[59] R. Yang, H. Jang, R. Stocker, K.K. Gleason, Synergistic prevention of biofouling in seawater desalination by zwitterionic surfaces and low-level chlorination, Adv. Mater. , 26 (2014) 1711-1718.

[60] A.P. Purdy, O. Kuyinu, Synthesis and dielectric properties of some zwitterionic polymers, Polym. Prepr. (Am. Chem. Soc., Div. Polym. Chem.), 50 (2009) 677.

[61] S. Mori, H.G. Barth, Size Exclusion Chromatography, Springer, Heidelberg, Germany, 2013.

[62] R. Revanur, B. McCloskey, K. Breitenkamp, B.D. Freeman, T. Emrick, Reactive amphiphilic graft copolymer coatings applied to poly (vinylidene fluoride) ultrafiltration membranes, Macromolecules, 40 (2007) 3624-3630.

[63] G. Odian, Principles of Polymerization, fourth ed., John Wiley \& Sons, Inc., Hoboken, New Jersey, 2004.

[64] G.-d. Kang, Y.-m. Cao, Application and modification of poly (vinylidene fluoride)(PVDF) membranes-A review, J. Membr. Sci., 463 (2014) 145-165.

[65] D.-J. Lin, C.-L. Chang, C.-K. Lee, L.-P. Cheng, Preparation and characterization of microporous PVDF/PMMA composite membranes by phase inversion in water/DMSO solutions, Eur. Polym. J., 42 (2006) 2407-2418.

[66] S.P. Nunes, K.V. Peinemann, Ultrafiltration membranes from PVDF/PMMA blends, J. Membr. Sci., 73 (1992) 25-35.

[67] N. Ochoa, M. Masuelli, J. Marchese, Effect of hydrophilicity on fouling of an emulsified oil wastewater with PVDF/PMMA membranes, J. Membr. Sci., 226 (2003) 203-211.

[68] S. Rajabzadeh, T. Maruyama, Y. Ohmukai, T. Sotani, H. Matsuyama, Preparation of PVDF/PMMA blend hollow fiber membrane via thermally induced phase separation (TIPS) method, Sep. Purif. Technol., 66 (2009) 76-83. 
[69] J.F. Hester, S.C. Olugebefola, A.M. Mayes, Preparation of pH-responsive polymer membranes by self-organization, J. Membr. Sci. , 208 (2002) 375-388.

[70] F. Liu, N.A. Hashim, Y. Liu, M.M. Abed, K. Li, Progress in the production and modification of PVDF membranes, J. Membr. Sci. , 375 (2011) 1-27.

[71] Q. Li, Q.-Y. Bi, T.-Y. Liu, X.-L. Wang, Resistance to protein and oil fouling of sulfobetaine-grafted poly(vinylidene fluoride) hollow fiber membrane and the electrolyteresponsive behavior in $\mathrm{NaCl}$ solution, Appl. Surf. Sci., 258 (2012) 7480-7489.

[72] Q. Yang, M. Ulbricht, Novel membrane adsorbers with grafted zwitterionic polymers synthesized by surface-Initiated ATRP and their salt-modulated permeability and protein binding properties, Chem. Mater., 24 (2012) 2943-2951.

[73] N. Hilal, O.O. Ogunbiyi, N.J. Miles, R. Nigmatullin, Methods employed for control of fouling in MF and UF membranes: a comprehensive review, Sep. Sci. Technol. , 40 (2005) 19572005.

[74] A. Asatekin, A.M. Mayes, Oil industry wastewater treatment with fouling resistant membranes containing amphiphilic comb copolymers, Environmental science \& technology, 43 (2009) 4487-4492.

[75] A. Asatekin, E.A. Olivetti, A.M. Mayes, Fouling resistant, high flux nanofiltration membranes from polyacrylonitrile-graft-poly (ethylene oxide), J. Membr. Sci. , 332 (2009) 6-12. [76] X. Lu, R. Weiss, Relationship between the glass transition temperature and the interaction parameter of miscible binary polymer blends, Macromolecules, 25 (1992) 3242-3246.

[77] E.K. Oikonomou, S. Tencé-Girault, P. Gérard, S. Norvez, Swelling of semi-crystalline PVDF by a PMMA-based nanostructured diblock copolymer: Morphology and mechanical properties, Polymer, 76 (2015) 89-97.

[78] Q. Guo, Completely miscible ternary blends-III. Poly (vinylidenefluoride)-poly (methyl methacrylate)-poly (vinyl acetate), Eur. Polym. J., 32 (1996) 1409-1413.

[79] M. Benz, W.B. Euler, Determination of the crystalline phases of poly (vinylidene fluoride) under different preparation conditions using differential scanning calorimetry and infrared spectroscopy, J. Appl. Polym. Sci., 89 (2003) 1093-1100.

[80] G. Bauduin, B. Boutevin, P. Gramain, A. Malinova, Poly (vinylidene fluoride)/poly (vinyl alcohol-co-vinyl acetate) blends: 1. compatibility study by differential scanning calorimetry (DSC), Eur. Polym. J., 35 (1999) 285-292.

[81] C. Jarusutthirak, G. Amy, J.-P. Croué, Fouling characteristics of wastewater effluent organic matter (EfOM) isolates on NF and UF membranes, Desalination, 145 (2002) 247-255.

[82] C. Reichenbach, M. Jekel, G. Amy, Rejection of wastewater effluent organic matter by microfiltration and ultrafiltration membranes for potable reuse, in: AWWA Water Quality Technology Conference, Nashville, Tennessee, USA, 2001.

[83] I. Moideen K, A.M. Isloor, B. Garudachari, A. Ismail, The effect of glycine betaine additive on the PPSU/PSF ultrafiltration membrane performance, Desalin. Water Treat., 57 (2016) 24788-24798. 


\section{Graphical Abstract}

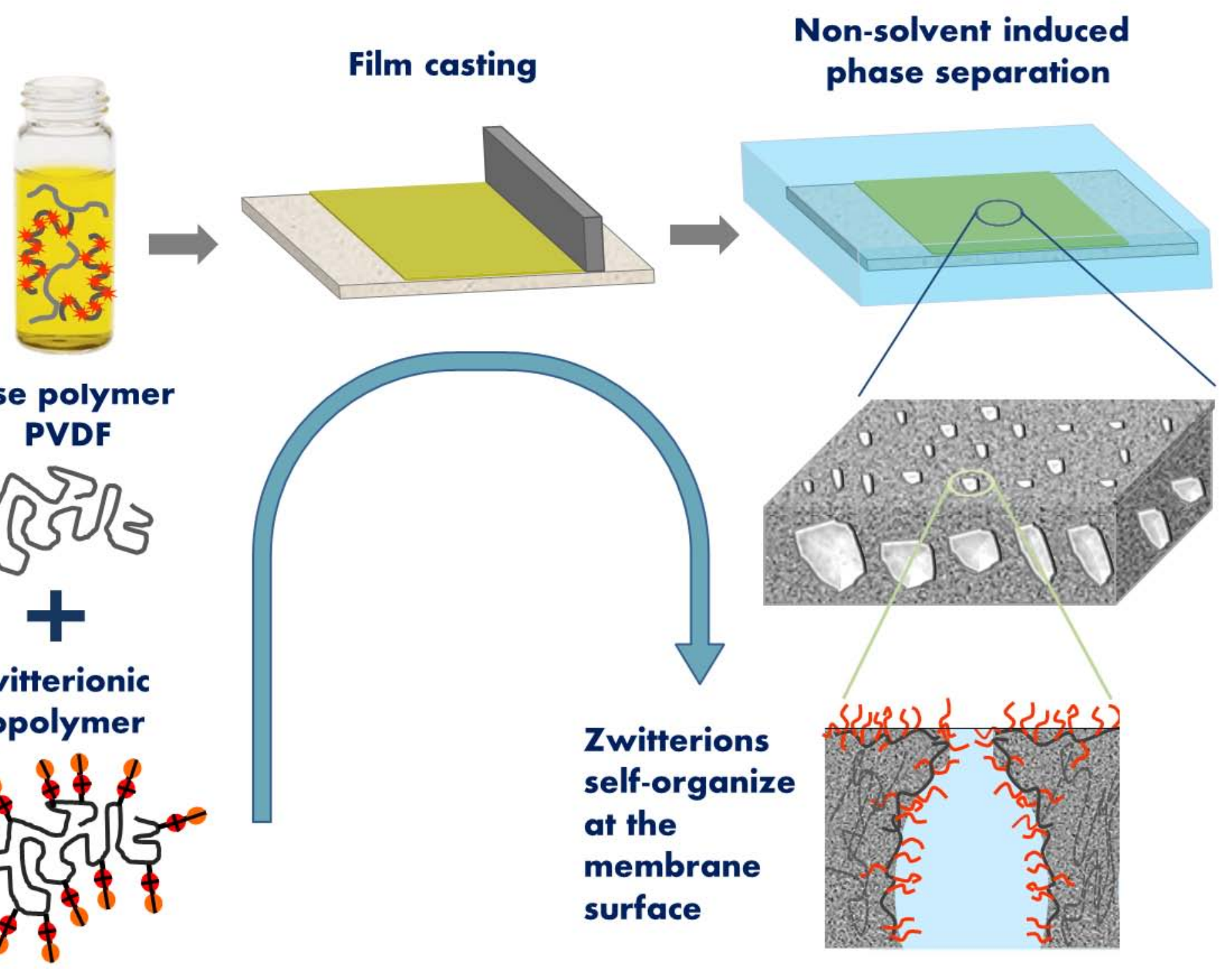

